\title{
Synthesis and Structure-Activity Relationships of $\mathrm{N}-(2-\mathrm{O} \times \mathrm{xo}-3-$ oxetanyl)amides as $\mathrm{N}$-Acylethanolamine-hydrolyzing Acid Amidase Inhibitors
}

\author{
Carlos Solorzano ${ }^{\mathrm{a}, \#}$, Francesca Antonietti ${ }^{\mathrm{b}, \#}$, Andrea Duranti $^{\mathrm{b}}$, Andrea Tontini ${ }^{\mathrm{b}}$, Silvia \\ Rivara $^{\mathrm{c}}$, Alessio Lodola ${ }^{\mathrm{c}}$, Federica Vacondio ${ }^{\mathrm{c}}$, Giorgio Tarzia ${ }^{\mathrm{b}}$, Daniele Piomellia,d, ${ }^{*}$, and \\ Marco Morc, ${ }^{*}$ \\ a Department of Pharmacology, University of California, Irvine, 360 MSRII, Irvine CA 92697-4625, \\ USA \\ b Dipartimento di Scienze del Farmaco e della Salute, Università degli Studi di Urbino "Carlo Bo", \\ Piazza del Rinascimento 6, I-61029 Urbino, Italy \\ c Dipartimento Farmaceutico, Università degli Studi di Parma, viale G. P. Usberti 27/A I-43124 \\ Parma, Italy \\ d Department of Drug Discovery and Development, Italian Institute of Technology, via Morego 30, \\ I-16163 Genova, Italy
}

\begin{abstract}
The fatty acid ethanolamides (FAEs) are a family of bioactive lipid mediators that include the endogenous agonist of peroxisome proliferator-activated receptor- $\alpha$, palmitoylethanolamide (PEA). FAEs are hydrolyzed intracellularly by either fatty acid amide hydrolase or $N$ acylethanolamine-hydrolyzing acid amidase (NAAA). Selective inhibition of NAAA by $(S)-\mathrm{N}-(2-$ oxo-3-oxetanyl)-3-phenylpropionamide [(S)-OOPP, 7a] prevents PEA degradation in mouse leukocytes and attenuates responses to proinflammatory stimuli. Starting from the structure of $7 \mathbf{a}$ a series of $\beta$-lactones was prepared and tested on recombinant rat NAAA to explore structureactivity relationships (SARs) for this class of inhibitors and improve their in vitro potency. Following the hypothesis that these compounds inhibit NAAA by acylation of the catalytic cysteine, we identified several requirements for recognition at the active site and obtained new potent inhibitors. In particular, $(S)-N$-(2-oxo-3-oxetanyl)biphenyl-4-carboxamide (7h) was more potent than 7a at inhibiting recombinant rat NAAA activity $\left(\mathbf{7 a}, \mathrm{IC}_{50}=420 \mathrm{nM} ; \mathbf{7 h}, \mathrm{IC}_{50}=115\right.$ $\mathrm{nM}$ ) in vitro and at reducing carrageenan-induced leukocyte infiltration in vivo.
\end{abstract}

\section{Introduction}

The fatty-acid ethanolamides (FAEs) are a family of bioactive lipid mediators that have stimulated pharmaceutical interest because drugs that block their deactivating metabolism may offer new ways to treat pain and inflammation.1 For example, inhibitors of the enzyme fatty acid amide hydrolase (FAAH) ${ }^{2}$ which catalyzes the hydrolysis of the endocannabinoid anandamide, are undergoing clinical investigations for the treatment of pain.3 Another endogenous FAE that has attracted considerable attention is palmitoylethanolamide (PEA), which exerts potent antiinflammatory 4 and analgesic5 effects, which are due to a large

\footnotetext{
"Corresponding authors: Marco Mor, Dipartimento Farmaceutico, Università degli Studi di Parma, Viale G.P. Usberti, 27/A, I-43124 Parma, Italy, Phone: (0039) 0521 905059, Fax: (0039) 0521 905006, mor@ unipr.it. Daniele Piomelli, Department of Drug Discovery and Development, Italian Institute of Technology, via Morego 30, I-16163 Genova, Italy, piomelli@uci.edu.

\#These authors contributed equally to the work
} 
extent to activation of the nuclear receptor peroxisome proliferator-activated receptor- $\alpha$ (PPAR- $\alpha$ )6,7 even though complementary mechanisms might also be involved. 8,9

PEA is produced in many mammalian tissues, including innate immune cells, 10 where a selective phospholipase D releases it from its membrane precursor, $N$ -

palmitoylphosphatidylethanolamine.11 PEA is deactivated by two intracellular amidases: FAAH and $N$-acylethanolamine-hydrolyzing acid amidase (NAAA).12,13,14 Potent FAAH inhibitors, such as the compound URB597,15 have been utilized to unmask the functions of the preferred FAAH substrate, anandamide, 16 but the search for potent and selective NAAA inhibitors is still at its beginning.17,18,19

NAAA preferentially hydrolyzes PEA over other FAEs and is localized to lysosomes. Despite its functional similarity with FAAH, NAAA shares no homology with this enzyme or other enzymes of the same 'amidase signature' family. ${ }^{14}$ Rather, NAAA is an N-terminal nucleophile hydrolase (Ntn) and belongs to the choloylglycine hydrolase family of hydrolases, which are characterized by the ability to cleave non-peptide amide bonds.13,20 Like other Ntn enzymes, NAAA is converted by proteolysis into a shorter active form upon incubation at acidic $\mathrm{pH} 21$. Processing of rodent NAAA renders cysteine 131 (Cys131) the $\mathrm{N}$-terminal amino acid and putative catalytic residue. Site-directed mutagenesis experiments have confirmed the importance of Cys131 for catalysis by NAAA.22,23

Compounds incorporating a $\beta$-lactone ring are known to interact covalently with biological nucleophiles, and some have been reported to inhibit enzymes that contain a catalytic cysteine, such as 3-hydroxy-3-methylglutaryl-CoA synthase (HMGS), 24 or threonine-based Ntn enzymes, like the proteasome.25 Screening a series of molecules that contain cysteinereactive warheads, we found that 2-oxo-3-oxetanylcarbamic acid benzyl ester (1, Table 1), which is known for its ability to inhibit a viral cysteine hydrolase, 26 was also a weak NAAA inhibitor. Structural modification of this compound allowed us to identify $(S)-N$-(2-oxo-3oxetanyl)-3-phenylpropanamide [(S)-OOPP, 7a , Table 1] as a potent non-competitive inhibitor of intracellular NAAA activity.23 Pharmacological experiments in vitro and in vivo have shown that 7a prevents PEA hydrolysis in activated inflammatory cells and dampens tissue reactions to various proinflammatory triggers. 23 This lactone derivative had revealed remarkable selectivity, showing no inhibition of several hydrolase enzymes that use lipids as substrates, including FAAH, monoacylglycerol lipase and diacylglycerol lipase type- $\alpha .23$

In the present study, we utilized the structures of the $\alpha$-acylamino- $\beta$-lactones 1 and $7 \mathbf{a} 23$ (Table 1) as starting points to explore structure-activity relationships (SARs) for compounds belonging to the chemical class of $N$-(2-oxo-3-oxetanyl)amides with the objective of discovering NAAA inhibitors with improved potency. In particular, we explored the role of the $\beta$-lactone ring and amide side chain, first by assessing stereoelectronic requirements in close proximity to the lactone ring, and next by optimizing the size and shape of the lipophilic tail of the amide moiety.

\section{Chemistry}

$N$-tert-butyloxycarbonyl-L-serine (2a) and $N$-tert-butyloxycarbonyl-D-serine (2b) were cyclized by means of a modified Mitsunobu reaction employing dimethyl azodicarboxylate (DMAD) and triphenylphosphine (Scheme 1).27 Deprotection of $\beta$-lactone derivatives 3a27 and $\mathbf{3 b}$ with trifluoroacetic acid in the presence of $p$-toluensulfonic acid gave the tosylate

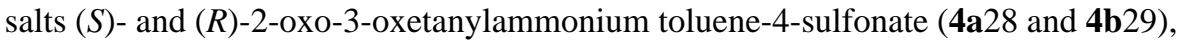
respectively.28,29 Alternatively, $\mathbf{4 a}$ can be obtained from the commercially available $(S)$-3(tritylamino)oxetan-2-one (Scheme 1).30 
The amides $7 \mathbf{a}, 23 \mathbf{b}, 31 \mathbf{d}-\mathbf{f}, \mathbf{i}, \mathbf{j}$ and $\mathbf{8 a} \cdot 23 \mathbf{j}$ were prepared by reaction of the corresponding acyl chloride $\mathbf{6 a}, \mathbf{b}, \mathbf{d}-\mathbf{f}, \mathbf{i}, \mathbf{j}$, , commercially available, and the salts $4 \mathbf{a}$ or $\mathbf{4 b}$ in the presence of triethylamine (Scheme 2). Epimerization of the stereogenic $\alpha$-centre was not observed.

The amides $\mathbf{7} \mathbf{c}, \mathbf{g}, \mathbf{h}, \mathbf{k}-\mathbf{n}$ were prepared by a two steps procedure starting from the corresponding carboxylic acid $\mathbf{9 c , g}, \mathbf{h}, \mathbf{k}-\mathbf{n}$ (Scheme 3). These acids, synthesized as reported below if not commercially available, were converted to acyl chlorides with oxalyl chloride and a catalytic amount of dimethylformamide. 32 The acyl chlorides were then reacted with 4a.

Compounds 10, 11a,j, 12 and 15 were synthesized as reported in Scheme 4. Compound 1033 was obtained by reacting L-serine with 3-phenylpropionyl chloride (6a) in aqueous sodium hydroxide. The $\gamma$-lactone derivatives $\mathbf{1 1 a} 34$ and $\mathbf{1 1} \mathbf{j}$ were synthesized by coupling (S)-3-aminodihydrofuran-2-one hydrobromide with 6a and naphthalene-2-carbonyl chloride $(\mathbf{6 j})$, respectively. Amide $\mathbf{1 2 2 3}$ was prepared by reacting $\mathbf{6 a}$ with cyclobutylamine. Cyclobutanone derivative 1523 was synthesized by the acid catalyzed reaction of 1,2bis(trimethylsilanyloxy)cyclobutene and 3-phenylpropionamide (14)35, the latter obtained through alkaline hydrolysis of 4-phenylpropionitrile (13) by slight modifications of a literature procedure. 36

The synthesis of threonine $\beta$-lactones 20a and 20b is reported in Scheme 5. The amino groups of L- and D-threonine were protected through treatment with di-tert-butyl dicarbonate in aqueous sodium bicarbonate to give $17 \mathbf{a} 37$ and 17b38, respectively, by means of slight modification of a literature procedure.39 Cyclization to $\beta$-lactones 18a40 and $\mathbf{1 8 b}$ was accomplished through treatment of $17 \mathbf{a}$ and $\mathbf{1 7 b}$, respectively, with benzotriazol-1-yloxytris(dimethylamino)phosphonium hexafluorophosphate (BOP reagent) by means of a literature procedure. 26 Subsequent deprotection of the amino group with trifluoroacetic acid in presence of $p$-toluensulfonic acid, following the same synthetic protocol adopted for $\mathbf{4 a}, \mathbf{b}$, gave the tosylate salts $(3 S, 4 R)$ - and $(3 R, 4 S)$-2-methyl-4-oxo-3oxetanylammonium toluene-4-sulfonate (19a41 and 19b). Finally, the triethylamine catalyzed coupling of these tosylate salts with $\mathbf{6 a}$ afforded the desired compounds $\mathbf{2 0 a}$ and 20b.

rac-3-(4-Phenylbutyl)oxetan-2-one $\mathbf{2 3}$ was prepared by means of slight modification of a literature procedure:42 alkanoic acid 22, obtained from unsaturated 2-methylene-6phenylhexanoic acid (21)43, was cyclized in aqueous sodium hydroxide (Scheme 6).

The syntheses of the carboxylic acids $9 \mathbf{g},{ }^{44} \mathbf{k}, 45 \mathbf{m}, 46 \mathbf{n}$ are reported in Scheme 7. $9 \mathbf{g}$ was obtained via a Suzuki cross-coupling reaction between 3-bromobenzaldehyde (24) and phenylboronic acid (25),47 and an oxidation of the resulting biphenyl-3-carbaldehyde to carboxylic acid by using aqueous potassium permanganate. The monoester $9 \mathbf{k}$ was prepared by treating the symmetric dicarboxylic acid $\mathbf{2 6}$ with ethylbromide by means of a slight modification of a literature procedure.48 The reaction of phenol with terephthaloyl dichloride (27), followed by the selective hydrolysis of the resulting terephthalic acid diphenyl ester with sodium carbonate, furnished $\mathbf{9 m}$. 9n49 was obtained by reaction between 4-hydroxybenzoic acid (28) and benzylbromide according to a literature procedure. 50

\section{Results and Discussion}

The new compounds were tested for their ability to inhibit heptadecenoylethanolamide hydrolysis by recombinant rat NAAA, heterologously expressed in HEK293 cells. IC $_{50}$ values are reported in Tables 1 and 2 . 
Previous work with compounds $\mathbf{1}, \mathbf{7} \mathbf{a}$ and $\mathbf{8 a} 23$ indicated that $(S)$-2-oxo-3-oxetanylamides offer a promising scaffold for SAR analysis and potency optimization, and that an intact $\beta$ lactone ring is essential for NAAA inhibition. Confirming those results, we found that compounds lacking the $\beta$-lactone moiety were entirely devoid of inhibitory activity $(\mathbf{1 0}, \mathbf{1 1 a}$, 12, 15).

The $\beta$-lactone group may contribute to NAAA inhibition in two different ways. Assuming that the sulfhydryl group of the active cysteine (Cys131 of rodent NAAA) interacts covalently with the 2-oxo-3-oxetane moiety of 7a, the nucleophilic attack could occur either at the 2-carbonyl, giving a thioester as the result of enzyme acylation (route "a", Figure 1), or at the 4-methylene group, resulting in enzyme alkylation (route "b", Figure 1). Both mechanisms are documented in the literature. For example, compound $\mathbf{1}$ irreversibly inhibits hepatitis A virus $3 \mathrm{C}$ protease through a mechanism involving the covalent attack of the enzyme nucleophile on the lactone methylene, leading to alkylation of catalytic Cys172.26,51 On the other hand, the $\beta$-lactone hymeglusin inhibits human HMGS by covalent modification of the active Cys129,52 but this effect is reversed by incubation with hydroxylamine, 53 and a thioester adduct resulting from the attack of the active Cys117 of Brassica juncea HMGS has been recently crystallized.54 A dialysis experiment on NAAA showed partial, but significant reversibility of inhibition by $7 \mathbf{a}$ (after inhibition by $10 \mu \mathrm{M}$ of $7 \mathbf{a}, 44 \pm 2 \%$ of initial NAAA activity is recovered following 12-hour dialysis), suggesting that cysteine acylation (route "a", Figure 1) is a likely mechanism.

To design new derivatives for further SAR exploration, we utilized a three-dimensional model of NAAA previously build by comparative modeling. This model had evidenced that essential features of the catalytic site of Ntn hydrolases 20 are retained by NAAA, revealing critical roles for amino acid residues involved in the oxyanion hole arrangement (Asn292), the stabilization of Cys131 basic nitrogen (Asp150) or ligand recognition (Asn209 and Tyr151); these roles have been confirmed by mutational analysis. 23

Using the NAAA model, we built the putative reaction intermediates resulting from nucleophilic attacks of the sulfhydryl group of Cys 131 on the lactone carbonyls of 7a and 8a (see Figure 2A and 2B, respectively). These covalent intermediates, built from docking poses consistent with cysteine acylation, showed favorable polar interactions of the lactone ring and the amide fragment with critical amino acid residues, and accommodation of the phenethyl chain in the lipophilic pocket lined by the aromatic ring of Tyr151, where the acyl chain of PEA might also be located.23

Following bond formation between the sulfur of Cys131 and the lactone carbonyl, and oxyanion accommodation into the putative oxyanion hole, the $\beta$-methylene groups of the lactone rings of 7a and 8a appeared to be surrounded by different stereoelectronic environments: the syn hydrogen in the $\beta$-methylene of $7 \mathbf{a}$ was close to the carbonyl group of Asp150 (Figure 2A), while the corresponding hydrogen of 8a pointed toward a free region of the active site (Figure 2B). We exploited this difference to design two derivatives aimed at testing the acylation hypothesis, as implemented by the NAAA model: the enantiomeric syn-methyl derivatives of 7a and 8a, compounds 20a and 20b. The complete loss of activity observed for compound 20a and the tolerance for the syn-methyl group of $\mathbf{2 0 b}$ (Table 1) supported our interaction model, which was then considered as a working hypothesis for further SAR exploration. The recognition role of the amide fragment of 7a and $\mathbf{8 a}$, illustrated in Figure 2, was also supported by the low potency of the racemic phenylbutyl lactone 23.

The model also implied that inhibitory potency could be improved by modulating the lipophilicity of the phenylpropionic chain of $7 \mathbf{a}$ [calculated $\operatorname{LogP}\left(\log \mathrm{P}_{\text {calc }}\right)$ : -0.43$], 55$ 
which may occupy the presumed acyl chain-binding pocket.20 However, while a shorter phenylacetic chain $\left(7 \mathbf{b}, \log \mathrm{P}_{\text {calc }}:-0.91\right)$ gave an expected increase in $\mathrm{IC}_{50}$, a decrease was not observed for the phenylheptanoic derivative $7 \mathbf{c}\left(\log \mathrm{P}_{\text {calc }}: 1.50\right)$, or for the heptanoic one 7d ( $\left.\log \mathrm{P}_{\text {calc: }}: 0.10\right)$. Based on these contrasting results, and considering that flexible structures typically provide ambiguous information about the steric requirements of their binding pockets, we turned our attention toward the more rigid class of aromatic amides (Table 2).

Starting from the benzamide derivative $7 \mathbf{e}\left(\log \mathrm{P}_{\text {calc }}:-0.64\right)$, addition of lipophilic substructures produced the expected increase in potency $\left(\mathbf{7 f}, \log \mathrm{P}_{\text {calc }}: 0.35\right)$. Steric factors also played a role, as evidenced by the comparison of the two naphthyl derivatives of similar lipophilicity $\mathbf{7 i}$ and $\mathbf{7 j}$. The latter was modified to test whether major SARs observed in the series of aliphatic amides were retained in the aromatic amide series. This possibility was confirmed by the lower potency of the $(R)$ enantiomer $\mathbf{8 j}$ and the inactivity of the $\gamma$-lactone 11j. Next, to explore the role of electronic effects, groups with electron-withdrawing or electron-donating properties were added at conjugated positions of the phenyl or naphthyl nuclei of $\mathbf{7 e}$ and $\mathbf{7 j}$, respectively. No clear influence of electronic effects on inhibitory potency emerged from compounds $7 \mathbf{k}-\mathbf{7 n}$. On the other hand, the role of steric effects on NAAA inhibition was confirmed by the different potencies of the two biphenyl derivatives $\mathbf{7 g}$ and $\mathbf{7 h}$ (Table 2 and Figure 3A). This suggests a preference of the inhibitor-binding site of NAAA for straight lipophilic structures, which appears to be a general feature of aromatic amides, as evidenced by the potency increases observed for all the derivatives of $7 \mathbf{e}$ having additional lipophilic groups in the para position (7f, 7j, $7 \mathbf{m}, 7 \mathbf{n}$ and $7 \mathbf{h})$.

Pharmacological characterization of the potent inhibitor $\mathbf{7 h}$ revealed that the compound inhibited NAAA with a rapid, noncompetitive and reversible mechanism (Table 3, 7h Figure 3B-D), which is consistent with the proposed acylation mechanism. We also tested whether inhibits NAAA activity and attenuates inflammation in vivo. We induced a localized inflammatory response in mice by implanting subcutaneously polyethylene sponges instilled with the proinflammatory polysaccharide carrageenan and collected infiltrating cells three days after surgery. As previously reported,23 carrageenan lowered PEA levels in leukocytes, an effect that was prevented, in a dose-dependent manner, by addition of compounds $\mathbf{7 h}$ and 7a to the sponges (Figure 4A). The compounds also reduced carrageenan-induced leukocyte infiltration with potencies that paralleled their ability to inhibit NAAA in vitro and normalize PEA levels in vivo (Figure 4B).

\section{Conclusions}

Figure 5 summarizes the SARs for the $\beta$-lactone NAAA inhibitors described in the present study. These SARs might be explained by hypothesizing a two-step mechanism of inhibition involving (i) inhibitor recognition at the substrate-binding site, and (ii) acylation of the active Cys131 by the lactone group. During the first step, the amide fragment attached to the lactone may undergo attractive polar interactions, favoring the correct positioning of the lactone warhead, as supported by the loss of potency of compounds lacking this fragment and by the stereoselectivity shown for positions 3 and 4 of the 2-oxo-3-oxetane portion. Moreover, the alkyl or aryl chain might assist inhibitor docking, by means of shapedependent lipophilic interactions with the enzyme pocket responsible for the recognition of the fatty acyl chain of PEA. Modification of these fragments led us to discover a $\beta$-lactonebased NAAA inhibitor, compound $\mathbf{7 h}$, which is potent at inhibiting NAAA in vitro and preventing carrageenan-induced inflammation after local administration in vivo. This compound may provide a chemical scaffold for the development of new tools to investigate the functional roles of NAAA and, possibly, of new anti-inflammatory and analgesic agents. 


\section{Experimental Section}

\section{(a) Chemicals, Materials, and Methods}

All reagents were purchased from Sigma-Aldrich, Lancaster, NovaBiochem, or Acros in the highest quality commercially available. Solvents were RP grade unless otherwise indicated. Dry tetrahydrofuran was distilled over sodium and benzophenone. Dry dimethylformamide, dichloromethane and triethylamine were used as supplied. Petroleum ether refers to alkanes with boiling point $40-60^{\circ} \mathrm{C}$. Melting points were determined on a Büchi B-540 capillary melting point apparatus. The structures of the unknown compounds were unambiguously assessed by MS, ${ }^{1} \mathrm{H}$ NMR and ${ }^{13} \mathrm{C}$ NMR and IR. MS (EI) spectra were recorded with a Fisons Trio $1000(70 \mathrm{eV})$ spectrometer; only molecular ions $\left(\mathrm{M}^{+}\right)$and base peaks are given. ESI-MS spectra were recorded with a Waters Micromass ZQ spectrometer in a positive mode using a nebulizing nitrogen gas at $400 \mathrm{~L} / \mathrm{min}$ and a temperature of $250{ }^{\circ} \mathrm{C}$, cone flow $40 \mathrm{~mL} / \mathrm{min}$, capillary $3.5 \mathrm{Kvolts}$ and cone voltage $60 \mathrm{~V}$; only molecular ions in positive or negative ion mode $[\mathrm{M}+\mathrm{H}]^{+}$or $[\mathrm{M}-\mathrm{H}]^{-}$are given. ${ }^{1} \mathrm{H}$ NMR and ${ }^{13} \mathrm{C}$ NMR spectra were recorded on a Bruker AC 200 or 50, respectively, spectrometer and analyzed using the WINNMR software package. Chemical shifts were measured by using the central peak of the solvent. IR spectra were obtained on a Nicolet Atavar 360 FT spectrometer. Optical rotations were measured on a Perkin Elmer 241 digital polarimeter using a sodium lamp $(589 \mathrm{~nm})$ as the light source; concentrations are expressed in $\mathrm{g} / 100 \mathrm{~mL}$, and the cell length was $1 \mathrm{dm}$. Enantiomeric excess (ee) values were determined by direct HPLC analysis with a Shimadzu spectrometer: pump LC-10AS, UV detector SPD-10A, integrator C-R6A and the chiral column Chiralpak AD-H $(0.46 \times 25 \mathrm{~cm})$ using a combination of $n$-hexane and isopropanol as eluent. Column chromatography purifications were performed under "flash" conditions using Merck 230-400 mesh silica gel. TLC was carried out on Merck silica gel 60 F254 plates which were visualized by exposure to ultraviolet light and by exposure to an aqueous solution of ceric ammonium molibdate. Reactions involving generation or consumption of $\beta$-lactone were conveniently followed by TLC using bromocresol green spray $(0.04 \%$ in $\mathrm{EtOH}$, made blue by $\mathrm{NaOH}$ ) followed by heating of the plate to detect the $\beta$-lactone as a yellow spot against a blue background. Compound purity was assessed by elemental analysis, on a ThermoQuest FlashEA 1112 Elemental Analyzer, for C, H and N; measured percent values were within \pm 0.4 of theoretical ones. All the tested compounds possessed a purity $>95 \%$.

(S) -(2-Oxo-3-oxetanyl)carbamic Acid tert-Butyl Ester (3a)-White solid. Mp 120$122{ }^{\circ} \mathrm{C} \mathrm{dec}\left(\mathrm{CHCl}_{3} / \text { hexane) (lit. 119.5-120.5 dec).27 [ } \alpha\right]^{20}{ }_{\mathrm{D}}-27$ (c 0.1, MeCN) [lit. -26.7 (c $1, \mathrm{MeCN})] .27 \mathrm{MS}(\mathrm{EI}) \mathrm{m} / \mathrm{z}: 188\left(\mathrm{M}^{+}\right), 57(100) .{ }^{1} \mathrm{H}$ NMR and IR are according to the literature. 27

(R)-(2-Oxo-3-oxetanyl)carbamic Acid tert-Butyl Ester (3b)-White solid. Mp 121$122{ }^{\circ} \mathrm{C} \mathrm{dec}\left(\mathrm{CHCl}_{3} /\right.$ hexane). $[\alpha]^{20}{ }_{\mathrm{D}}+26.7$ (c 1, MeCN). MS (EI) $\mathrm{m} / z: 188\left(\mathrm{M}^{+}\right), 57$

(100). ${ }^{1} \mathrm{H}$ NMR $\left(\mathrm{CDCl}_{3}\right) \delta: 1.47(\mathrm{~s}, 9 \mathrm{H}), 4.41-4.51(\mathrm{~m}, 2 \mathrm{H}), 4.85$ (br s, $\left.1 \mathrm{H}\right), 5.06-5.19(\mathrm{~m}$, 1H) ppm. IR (Nujol) $v_{\max }: 3357,1844,1717,1683 \mathrm{~cm}^{-1}$.

(S)-2-Oxo-3-oxetanylammonium Toluene-4-sulfonate (4a).28-White solid. Mp and ${ }^{1} \mathrm{H}$ NMR are according to the literature. 28

(R)-2-Oxo-3-oxetanylammonium Toluene-4-sulfonate (4b).29-White solid. ${ }^{1} \mathrm{H}$ NMR is according to the literature. 29

General Procedure for the Synthesis of Amides 7a,b,d-f,i,j,8a,j-To a stirred mixture of $4 \mathbf{a}(0.260 \mathrm{~g}, 1 \mathrm{mmol})$ in dry $\mathrm{CH}_{2} \mathrm{Cl}_{2}(4 \mathrm{~mL})$, at $0{ }^{\circ} \mathrm{C}$ and under $\mathrm{N}_{2}$ atmosphere, 
$\mathrm{Et}_{3} \mathrm{~N}(0.304 \mathrm{~g}, 0.42 \mathrm{~mL}, 3 \mathrm{mmol})$ and the suitable acyl chloride $\mathbf{6 a}, \mathbf{b}, \mathbf{d}-\mathbf{f}, \mathbf{i}, \mathbf{j}$ (1.5 mmol) were added. The mixture was stirred at $0{ }^{\circ} \mathrm{C}$ for $0.5 \mathrm{~h}$ and at room temperature for $2 \mathrm{~h}$, then concentrated. Purification of the residue by column chromatography (cyclohexane/EtOAc $1: 1$ for $\mathbf{7 d - f}, \mathbf{i}, \mathbf{j}, \mathbf{8 j} ; 1: 1$ to $3: 7$ for $\mathbf{7 a}, \mathbf{8 a} ; 4: 6$ for $\mathbf{7 b}$ ) and recrystallization gave $\mathbf{7 a}, \mathbf{b}, \mathbf{d}-\mathbf{f}, \mathbf{i}, \mathbf{j}$, $8 \mathbf{a}, \mathbf{j}$.

(S)-N-(2-Oxo-3-oxetanyl)-3-phenylpropionamide (7a).23: White solid. Yield: $60 \%$ (0.132 g). $\mathrm{Mp} 104-106{ }^{\circ} \mathrm{C}\left[\mathrm{CH}_{3} \mathrm{C}(\mathrm{O}) \mathrm{CH}_{3} /\right.$ petroleum ether]. $[\alpha]^{20} \mathrm{D}-13$ (c 0.5, MeOH). Ee > 98\% [Chiral HPLC: AD-H; flow: $1 \mathrm{~mL} / \mathrm{min}$; $\lambda_{\max }: 220 \mathrm{~nm}$; eluent: $n$-hexane/isopropanol 85:15; $\left.t_{\mathrm{S}}: 8.9 \mathrm{~min}\right] . \mathrm{MS}(\mathrm{EI}) \mathrm{m} / z: 219\left(\mathrm{M}^{+}\right), 91(100) .{ }^{1} \mathrm{H} \mathrm{NMR}\left(\mathrm{CDCl}_{3}\right) \delta: 2.57(\mathrm{t}, 2 \mathrm{H}, J=7.5 \mathrm{~Hz})$, $2.99(\mathrm{t}, 2 \mathrm{H}, J=7.5 \mathrm{~Hz}), 4.34(\mathrm{t}, 1 \mathrm{H}, J=4.9 \mathrm{~Hz}), 4.43\left(\mathrm{dd}, 1 \mathrm{H}, J_{1}=5.2 \mathrm{~Hz}, J_{2}=6.5\right), 5.10$ $5.19(\mathrm{~m}, 1 \mathrm{H}), 5.97$ (br d, 1H), 7.18-7.36 (m, 5H) ppm. ${ }^{13} \mathrm{C} \mathrm{NMR}\left(\mathrm{CDCl}_{3}\right)$ 8: 31.2, 37.7, $58.4,66.1,126.5,128.3,128.7,140.2,168.4,172.5 \mathrm{ppm}$. IR (Nujol) $v_{\max }: 3333,1832,1652$ $\mathrm{cm}^{-1}$. Anal. $\left(\mathrm{C}_{12} \mathrm{H}_{13} \mathrm{NO}_{3}\right) \mathrm{C}, \mathrm{H}, \mathrm{N}$.

(R)-N-(2-Oxo-3-oxetanyl)-3-phenylpropionamide (8a): White solid. Yield: $33 \%(0.072$ g). $\mathrm{Mp} 100-103{ }^{\circ} \mathrm{C}\left[\mathrm{CH}_{3} \mathrm{C}(\mathrm{O}) \mathrm{CH}_{3} /\right.$ petroleum ether]. $[\alpha]^{20}{ }_{\mathrm{D}}+11(c 1, \mathrm{MeOH}) . \mathrm{Ee}>98 \%$ (experimental conditions are identical with those for $7 \mathbf{a} ; t_{\mathrm{R}}: 12.3 \mathrm{~min}$ ). MS (EI) $\mathrm{m} / z: 219$ $\left(\mathrm{M}^{+}\right), 91(100) .{ }^{1} \mathrm{H}$ NMR $\left(\mathrm{CDCl}_{3}\right) \delta: 2.57(\mathrm{t}, 2 \mathrm{H}, J=7.5 \mathrm{~Hz}), 2.99(\mathrm{t}, 2 \mathrm{H}, J=7.5 \mathrm{~Hz}), 4.34$ $(\mathrm{t}, 1 \mathrm{H}, J=4.9 \mathrm{~Hz}), 4.43\left(\mathrm{dd}, 1 \mathrm{H}, J_{1}=5.2 \mathrm{~Hz}, J_{2}=6.5\right), 5.08-5.18(\mathrm{~m}, 1 \mathrm{H}), 6.11(\mathrm{br} \mathrm{d}, 1 \mathrm{H})$, 7.17-7.34 (m, 5H) ppm. ${ }^{13} \mathrm{C} \mathrm{NMR}\left(\mathrm{CDCl}_{3}\right) \delta: 31.2,37.7,58.4,66.1,126.5,128.3,128.7$, $140.2,168.4,172.5 \mathrm{ppm}$. IR (Nujol) $v_{\max }: 3349,1845,1646 \mathrm{~cm}^{-1}$. Anal. $\left(\mathrm{C}_{12} \mathrm{H}_{13} \mathrm{NO}_{3}\right) \mathrm{C}$, $\mathrm{H}, \mathrm{N}$.

(S)- $N$-(2-Ox0-3-oxetanyl)-2-phenylacetamide (7b).31: White solid. Yield: 10\% (0.021 g). $\mathrm{Mp} 112-114^{\circ} \mathrm{C} \operatorname{dec}\left(\mathrm{CHCl}_{3} /\right.$ hexane) (lit. $\left.122-123^{\circ} \mathrm{C}\right) .31[\alpha]^{20} \mathrm{D}-14.1$ (c 0.34, MeOH). MS (EI) $m / z: 205\left(\mathrm{M}^{+}\right), 91(100) .{ }^{1} \mathrm{H}$ NMR $\left(\mathrm{CDCl}_{3}\right) \delta: 3.67(\mathrm{~s}, 2 \mathrm{H}), 4.41-4.46(\mathrm{~m}, 2 \mathrm{H})$, 5.06-5.16 (m, 1H), 6.00 (br s, $1 \mathrm{H}), 7.25-7.43(\mathrm{~m}, 5 \mathrm{H}) \mathrm{ppm} .{ }^{13} \mathrm{C} \mathrm{NMR}\left(\mathrm{CDCl}_{3}\right) \delta: 43.1$, $58.5,65.9,127.9,129.3,129.5,133.6,168.2,171.3 \mathrm{ppm}$. IR (Nujol) $v_{\max }: 3321,1845,1814$, $1651 \mathrm{~cm}^{-1}$. Anal. $\left(\mathrm{C}_{11} \mathrm{H}_{11} \mathrm{NO}_{3}\right) \mathrm{C}, \mathrm{H}, \mathrm{N}$.

(S)- $N$-(2-Oxo-3-oxetanyl)heptanamide (7d): White fluffy crystals. Yield: 49\% (0.097 g). Mp 103-105 ${ }^{\circ} \mathrm{C}\left(\mathrm{CHCl}_{3} / n\right.$-hexane). $[\alpha]^{20}{ }_{\mathrm{D}}-16.0$ (c 0.45, MeOH). MS (ESI) $m / z: 200.5[\mathrm{M}$ $+\mathrm{H}]^{+} .{ }^{1} \mathrm{H}$ NMR $\left[\mathrm{CD}_{3} \mathrm{C}(\mathrm{O}) \mathrm{CD}_{3}\right] \delta: 0.88(\mathrm{t}, 3 \mathrm{H}, J=6.5 \mathrm{~Hz}), 1.25-1.36(\mathrm{~m}, 6 \mathrm{H}), 1.52-1.67$ $(\mathrm{m}, 2 \mathrm{H}), 2.24(\mathrm{t}, 2 \mathrm{H}, J=7.4 \mathrm{~Hz}), 4.43(\mathrm{~d}, 2 \mathrm{H}, J=5.8 \mathrm{~Hz}), 5.21-5.31(\mathrm{~m}, 1 \mathrm{H}), 7.86(\mathrm{br} \mathrm{s}$, 1H) ppm. ${ }^{13} \mathrm{C}$ NMR $\left[\mathrm{CD}_{3} \mathrm{C}(\mathrm{O}) \mathrm{CD}_{3}\right]$ $\delta: 13.4,22.2,25.1,28.6,31.4,35.1,58.5,65.1,169.3$, 172.9 ppm. IR (Nujol) v $v_{\max }: 3275,1861,1648,1534 \mathrm{~cm}^{-1}$. Anal. $\left(\mathrm{C}_{10} \mathrm{H}_{17} \mathrm{NO}_{3}\right) \mathrm{C}, \mathrm{H}, \mathrm{N}$.

(S)-N-(2-Oxo-3-oxetanyl)benzamide (7e): White crystals. Yield: $41 \%$ (0.078 g). Mp 113$114{ }^{\circ} \mathrm{C}\left[\mathrm{CH}_{3} \mathrm{C}(\mathrm{O}) \mathrm{CH}_{3} /\right.$ petroleum ether]. $[\alpha]^{20}{ }_{\mathrm{D}}-28.4$ (c 0.5, MeCN). MS (EI) $\mathrm{m} / z: 191$ $\left(\mathrm{M}^{+}\right), 77(100) .{ }^{1} \mathrm{H}$ NMR $\left[\mathrm{CD}_{3} \mathrm{C}(\mathrm{O}) \mathrm{CD}_{3}\right] \delta: 4.52-4.63(\mathrm{~m}, 2 \mathrm{H}), 5.47-5.57(\mathrm{~m}, 1 \mathrm{H}), 7.46-$ $7.60(\mathrm{~m}, 3 \mathrm{H}), 7.91-7.97(\mathrm{~m}, 2 \mathrm{H}), 8.63(\mathrm{br} \mathrm{s}, 1 \mathrm{H}) \mathrm{ppm} .{ }^{13} \mathrm{C} \mathrm{NMR}\left[\mathrm{CD}_{3} \mathrm{C}(\mathrm{O}) \mathrm{CD}_{3}\right]$ \&: 58.8, $65.1,127.3,128.5,131.9,133.2,166.7,169.2 \mathrm{ppm}$. IR (Nujol) $v_{\max }: 3272,1849,1827,1647$ $\mathrm{cm}^{-1}$. Anal. $\left(\mathrm{C}_{10} \mathrm{H}_{9} \mathrm{NO}_{3}\right) \mathrm{C}, \mathrm{H}, \mathrm{N}$.

(S)-4-Ethyl- $N$-(2-oxo-3-oxetanyl)benzamide (7f): White fluffy crystals. Yield: $40 \%$ (0.088 g). $\mathrm{Mp} 118-119^{\circ} \mathrm{C}\left[\mathrm{CH}_{3} \mathrm{C}(\mathrm{O}) \mathrm{CH}_{3} /\right.$ petroleum ether $]$. $[\alpha]^{20} \mathrm{D}-9.5$ (c 0.6, MeOH). MS (EI) $m / z: 219\left(\mathrm{M}^{+}\right), 133(100) .{ }^{1} \mathrm{H}$ NMR $\left[\mathrm{CD}_{3} \mathrm{C}(\mathrm{O}) \mathrm{CD}_{3}\right] \delta: 1.23(\mathrm{t}, 3 \mathrm{H}, J=7.5 \mathrm{~Hz}), 2.70(\mathrm{q}, 2 \mathrm{H}$, $J=7.5 \mathrm{~Hz}), 4.50-4.63(\mathrm{~m}, 2 \mathrm{H}), 5.45-5.55(\mathrm{~m}, 1 \mathrm{H}), 7.31-7.36(\mathrm{~m}, 2 \mathrm{H}), 7.82-7.89(\mathrm{~m}, 2 \mathrm{H})$, 8.54 (br s, $1 \mathrm{H}) \mathrm{ppm} .{ }^{13} \mathrm{C}$ NMR $\left[\mathrm{CD}_{3} \mathrm{C}(\mathrm{O}) \mathrm{CD}_{3}\right] \delta: 14.8,28.4,58.8,65.1,127.4,128.0,130.6$, 148.6, 166.6, $169.3 \mathrm{ppm}$. IR (Nujol) $v_{\max }: 3298,1832,1642 \mathrm{~cm}^{-1}$. Anal. $\left(\mathrm{C}_{12} \mathrm{H}_{13} \mathrm{NO}_{3}\right) \mathrm{C}$, $\mathrm{H}, \mathrm{N}$. 
(S)- $N$-(2-Oxo-3-oxetanyl)-1-naphthamide (7i): Off-white crystals. Yield: $67 \%(0.161 \mathrm{~g})$.

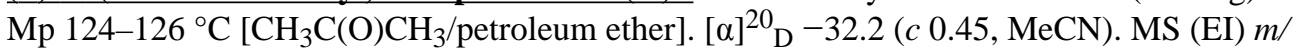
$z: 241\left(\mathrm{M}^{+}\right), 127(100) .{ }^{1} \mathrm{H}$ NMR $\left[\mathrm{CD}_{3} \mathrm{C}(\mathrm{O}) \mathrm{CD}_{3}\right] \delta: 4.63(\mathrm{dd}, 1 \mathrm{H}, J=4.6,6.7 \mathrm{~Hz}), 4.74(\mathrm{t}$, $1 \mathrm{H}, J=4.7 \mathrm{~Hz}), 5.56-5.65(\mathrm{~m}, 1 \mathrm{H}), 7.51-7.62(\mathrm{~m}, 3 \mathrm{H}), 7.78(\mathrm{dd}, 1 \mathrm{H}, J=1.3,7.1 \mathrm{~Hz}), 7.95-$ $8.08(\mathrm{~m}, 2 \mathrm{H}), 8.39-8.44(\mathrm{~m}, 1 \mathrm{H}), 8.55(\mathrm{br} \mathrm{s}, 1 \mathrm{H}) \mathrm{ppm} .{ }^{13} \mathrm{C} \mathrm{NMR}\left[\mathrm{CD}_{3} \mathrm{C}(\mathrm{O}) \mathrm{CD}_{3}\right]$ 8: 58.9, $65.2,124.7,125.5,125.6,126.4,127.0,128.3,130.3,130.9,132.9,133.8,169.1,169.2 \mathrm{ppm}$. IR (Nujol) $v_{\max }: 3291,1842,1637 \mathrm{~cm}^{-1}$. Anal. $\left(\mathrm{C}_{14} \mathrm{H}_{11} \mathrm{NO}_{3}\right) \mathrm{C}, \mathrm{H}, \mathrm{N}$.

(S)-N-(2-Oxo-3-oxetanyl)-2-naphthamide (7j): White solid. Yield: $47 \%(0.113 \mathrm{~g})$. Mp 193-195 ${ }^{\circ} \mathrm{C}$, decomposition and shrinkage starting from $180^{\circ} \mathrm{C}$, sealed capillary tube $\left[\mathrm{CH}_{3} \mathrm{C}(\mathrm{O}) \mathrm{CH}_{3} /\right.$ petroleum ether]. $[\alpha]^{20}{ }_{\mathrm{D}}-17(\mathrm{c} 0.1, \mathrm{MeCN})$. MS (ESI) $\mathrm{m} / \mathrm{z}: 240.5$ [M$\mathrm{H}]^{+} .{ }^{1} \mathrm{H}$ NMR $\left[\mathrm{CD}_{3} \mathrm{C}(\mathrm{O}) \mathrm{CD}_{3}\right]$ 8: 4.56-4.68 (m, 2H), 5.54-5.64 (m, 1H), 7.56-7.69 (m, 2H), 7.96-8.06 (m, 4H), $8.52(\mathrm{~d}, 1 \mathrm{H}, J=1 \mathrm{~Hz}), 8.80(\mathrm{br} \mathrm{d}, 1 \mathrm{H}) \mathrm{ppm} .{ }^{13} \mathrm{C} \mathrm{NMR}\left[\mathrm{CD}_{3} \mathrm{C}(\mathrm{O}) \mathrm{CD}_{3}\right]$ $\delta: 58.8,65.1,123.8,126.9,127.7,127.9,128.3,129.0,130.5,132.6,135.0,166.8,169.3$ ppm. IR (Nujol) $v_{\max }: 3270,1825,1647 \mathrm{~cm}^{-1}$. Anal. $\left(\mathrm{C}_{14} \mathrm{H}_{11} \mathrm{NO}_{3}\right) \mathrm{C}, \mathrm{H}, \mathrm{N}$.

(R)-N-(2-Oxo-3-oxetanyl)-2-naphthamide (8j): White solid. Yield: $20 \%$ (0.048 g). Mp $195{ }^{\circ} \mathrm{C}$, decomposition and shrinkage starting from $175^{\circ} \mathrm{C}\left[\mathrm{CH}_{3} \mathrm{C}(\mathrm{O}) \mathrm{CH}_{3} /\right.$ petroleum ether $]$. $[\alpha]^{20}{ }_{\mathrm{D}}+17(c 0.1, \mathrm{MeCN})$. MS (EI) $m / z: 241\left(\mathrm{M}^{+}\right), 141(100) .{ }^{1} \mathrm{H}$ NMR $\left[\mathrm{CD}_{3} \mathrm{C}(\mathrm{O}) \mathrm{CD}_{3}\right] \delta$ : 4.56-4.68 (m, 2H), 5.54-5.64 (m, 1H), 7.57-7.68 (m, 2H), 7.96-8.06 (m, 4H), 8.52 (d, 1H, $J$ $=1 \mathrm{~Hz}), 8.80(\mathrm{br} \mathrm{d}, 1 \mathrm{H}) \mathrm{ppm} .{ }^{13} \mathrm{C} \mathrm{NMR}\left[\mathrm{CD}_{3} \mathrm{C}(\mathrm{O}) \mathrm{CD}_{3}\right] \delta: 58.8,65.1,123.8,126.9,127.7$, $127.9,128.3,129.0,130.5,132.6,135.0,166.8,169.3 \mathrm{ppm}$. IR (Nujol) $v_{\max }: 3262,1824$, $1645 \mathrm{~cm}^{-1}$. Anal. $\left(\mathrm{C}_{14} \mathrm{H}_{11} \mathrm{NO}_{3}\right) \mathrm{C}, \mathrm{H}, \mathrm{N}$.

General Procedure for the Synthesis of Amides 7c,g,h,k-n-To a stirred solution of the suitable acid $9 \mathbf{c}, \mathbf{g}, \mathbf{h}, \mathbf{k}-\mathbf{n}(2 \mathrm{mmol})$ in dry $\mathrm{CH}_{2} \mathrm{Cl}_{2}(5 \mathrm{~mL})$, at $0{ }^{\circ} \mathrm{C}$ and under $\mathrm{N}_{2}$ atmosphere, $(\mathrm{COCl})_{2}(0.381 \mathrm{~g}, 0.26 \mathrm{~mL}, 3 \mathrm{mmol})$ and a catalytic amount of DMF were added. After gas evolution the mixture was stirred at room temperature for $3 \mathrm{~h}(16 \mathrm{~h}, 7 \mathrm{l} ; 6 \mathrm{~h}$, $7 \mathbf{m})$ and concentrated; the resulting crude acid chloride was used as such in the next step. A mixture of the acid chloride ( $2 \mathrm{mmol}), \mathbf{4 a}(0.337 \mathrm{~g}, 1.3 \mathrm{mmol}), \mathrm{Et}_{3} \mathrm{~N}(6.7 \mathrm{mmol}, \mathbf{7 c}, \mathbf{g} ; 8$ $\mathrm{mmol}, \mathbf{7 h}, \mathbf{k} ; 5.5 \mathrm{mmol}, \mathbf{7 n} ; 3.6 \mathrm{mmol}, \mathbf{7 l}, \mathbf{m}$ ) (a catalytic amount of 4-dimethylaminopyridine in the case of $\mathbf{7} \mathbf{c}, \mathbf{g}$ is necessary) in dry $\mathrm{CH}_{2} \mathrm{Cl}_{2}(8 \mathrm{~mL}, \mathbf{7} \mathbf{c}, \mathbf{g}, \mathbf{k} ; 4 \mathrm{~mL}, \mathbf{7 l}, \mathbf{m})$ or dry THF (20 $\mathrm{mL}, 7 \mathbf{h} ; 8 \mathrm{~mL}, \mathbf{7 n}$ ) was stirred at $0{ }^{\circ} \mathrm{C}$ for $0.5 \mathrm{~h}$ and at room temperature for $3 \mathrm{~h}$ under $\mathrm{N}_{2}$ atmosphere, then concentrated. In the case of $\mathbf{7 m}$ further amounts of $4 \mathbf{a}(0.168 \mathrm{~g}, 0.65$ $\mathrm{mmol})$ and $\mathrm{Et}_{3} \mathrm{~N}(0.101 \mathrm{~g}, 0.14 \mathrm{~mL}, 1 \mathrm{mmol})$ were added and the mixture was stirred for further $3 \mathrm{~h}$, then concentrated. Purification of the residue by column chromatography (cyclohexane/EtOAc 1:1 for $\mathbf{7} \mathbf{c}, \mathbf{g}, \mathbf{h}, \mathbf{n} ; \mathrm{CH}_{2} \mathrm{Cl}_{2} / \mathrm{EtOAc}$ 9:1 for $\mathbf{7 k - m}$ ) and recrystallization gave $\mathbf{7 c}, \mathbf{g}, \mathbf{h}, \mathbf{k}-\mathbf{n}$.

(S)-N-(2-Oxo-3-oxetanyl)-7-phenylheptanamide (7c): White fluffy solid. Yield: $39 \%$ $(0.139 \mathrm{~g}) . \mathrm{Mp} 98-99{ }^{\circ} \mathrm{C}\left[\mathrm{CH}_{3} \mathrm{C}(\mathrm{O}) \mathrm{CH}_{3} /\right.$ petroleum ether $]$. $[\alpha]^{20}{ }_{\mathrm{D}}-16.2(c 0.5, \mathrm{MeOH}) . \mathrm{MS}$ (ESI) $m / z: 274.6[\mathrm{M}-\mathrm{H}]^{+} .{ }^{1} \mathrm{H}$ NMR $\left(\mathrm{CDCl}_{3}\right) \delta: 1.32-1.39(\mathrm{~m}, 4 \mathrm{H}), 1.55-1.73(\mathrm{~m}, 4 \mathrm{H}), 2.25$ $(\mathrm{t}, 2 \mathrm{H}, J=7.5 \mathrm{~Hz}), 2.61(\mathrm{t}, 2 \mathrm{H}, J=7.6 \mathrm{~Hz}), 4.40-4.50(\mathrm{~m}, 2 \mathrm{H}), 5.15-5.24(\mathrm{~m}, 1 \mathrm{H}), 6.14(\mathrm{br}$ d, $1 \mathrm{H}, J=7.5 \mathrm{~Hz}), 7.14-7.33(\mathrm{~m}, 5 \mathrm{H}) \mathrm{ppm} .{ }^{13} \mathrm{C} \mathrm{NMR}\left(\mathrm{CDCl}_{3}\right) \delta: 25.1,28.8,29.0,31.2$, $35.8,58.4,66.3,125.6,128.2,128.4,142.6,168.5,173.3$ ppm. IR (Nujol) $v_{\max }: 3331,1853$, $1833,1649 \mathrm{~cm}^{-1}$. Anal. $\left(\mathrm{C}_{16} \mathrm{H}_{21} \mathrm{NO}_{3}\right) \mathrm{C}, \mathrm{H}, \mathrm{N}$.

$(S)$ - $N$-(2-Oxo-3-oxetanyl)biphenyl-3-carboxamide (7g): White fluffy solid. Yield: $68 \%$ $\left(0.236\right.$ g). Mp $116-117^{\circ} \mathrm{C}\left[\mathrm{CH}_{3} \mathrm{C}(\mathrm{O}) \mathrm{CH}_{3} /\right.$ petroleum ether]. $[\alpha]^{20}{ }_{\mathrm{D}}-20$ (c 0.55, MeCN). MS (ESI) $\mathrm{m} / z: 268.0[\mathrm{M}+\mathrm{H}]^{+} .{ }^{1} \mathrm{H}$ NMR $\left[\mathrm{CD}_{3} \mathrm{C}(\mathrm{O}) \mathrm{CD}_{3}\right] \delta: 4.54-4.66(\mathrm{~m}, 2 \mathrm{H}), 5.51-5.61$ $(\mathrm{m}, 1 \mathrm{H}), 7.37-7.74(\mathrm{~m}, 6 \mathrm{H}), 7.86-7.96(\mathrm{~m}, 2 \mathrm{H}), 8.20-8.22(\mathrm{~m}, 1 \mathrm{H}), 8.75(\mathrm{br} \mathrm{s}, 1 \mathrm{H})$ ppm. ${ }^{13} \mathrm{C}$ NMR $\left[\mathrm{CD}_{3} \mathrm{C}(\mathrm{O}) \mathrm{CD}_{3}\right]$ 8: 58.9, 65.1, 125.7, 126.4, 126.9, 127.8, 129.0, 129.2, 
130.3, 133.8, 140.0, 141.3, 166.6, 169.2 ppm. IR (Nujol) $v_{\max }: 3314,1856,1824,1638$ $\mathrm{cm}^{-1}$. Anal. $\left(\mathrm{C}_{16} \mathrm{H}_{13} \mathrm{NO}_{3}\right) \mathrm{C}, \mathrm{H}, \mathrm{N}$.

(S)-N-(2-Oxo-3-oxetanyl)biphenyl-4-carboxamide (7h): Off-white solid. Yield: $46 \%$ $(0.160 \mathrm{~g}) . \mathrm{Mp} 218-220^{\circ} \mathrm{C}$, decomposition with colour change and shrinkage starting from $146{ }^{\circ} \mathrm{C}$, sealed capillary tube $\left[\mathrm{CH}_{3} \mathrm{C}(\mathrm{O}) \mathrm{CH}_{3} /\right.$ petroleum ether $] .[\alpha]^{20}{ }_{\mathrm{D}}-20(c 0.55, \mathrm{MeCN})$. MS (EI) m/z: $267\left(\mathrm{M}^{+}\right), 167$ (100). ${ }^{1} \mathrm{H}$ NMR $\left[\mathrm{CD}_{3} \mathrm{C}(\mathrm{O}) \mathrm{CD}_{3}\right] \delta: 4.53-4.65(\mathrm{~m}, 2 \mathrm{H}), 5.50-$ $5.59(\mathrm{~m}, 1 \mathrm{H}), 7.38-7.55(\mathrm{~m}, 3 \mathrm{H}), 7.70-7.84(\mathrm{~m}, 4 \mathrm{H}), 8.00-8.07$ (m, 2H), 8.68 (br d, 1H, $J=$ $7 \mathrm{~Hz}) \mathrm{ppm} .{ }^{13} \mathrm{C} \mathrm{NMR}\left[\mathrm{CD}_{3} \mathrm{C}(\mathrm{O}) \mathrm{CD}_{3}\right] \delta: 58.8,65.1,126.9,127.0,128.0,128.1,129.0$, $131.9,139.7,144.4,166.4,169.2 \mathrm{ppm}$. IR (Nujol) $v_{\max }: 3270,1827,1641 \mathrm{~cm}^{-1}$. Anal. $\left(\mathrm{C}_{16} \mathrm{H}_{13} \mathrm{NO}_{3}\right) \mathrm{C}, \mathrm{H}, \mathrm{N}$.

(S)-6-(2-Oxo-3-oxetanylcarbamoyl)naphthalene-2-carboxylic Acid Ethyl Ester (7k):

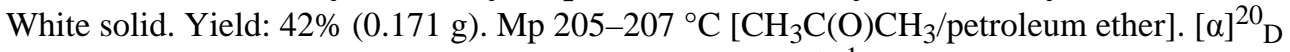
$-19\left[c 0.1,\left(\mathrm{CH}_{3} \mathrm{C}(\mathrm{O}) \mathrm{CH}_{3}\right)\right]$. MS (ESI) m/z: $313.8[\mathrm{M}+\mathrm{H}]^{+} .{ }^{1} \mathrm{H}$ NMR (DMSO-d $\left.)_{6}\right) \delta: 1.37(\mathrm{t}$, $3 \mathrm{H}, J=7.1 \mathrm{~Hz}), 4.39(\mathrm{q}, 2 \mathrm{H}, J=7.1 \mathrm{~Hz}), 4.48-4.53(\mathrm{~m}, 2 \mathrm{H}), 5.43-5.52(\mathrm{~m}, 1 \mathrm{H}), 7.97-8.08$ $(\mathrm{m}, 2 \mathrm{H}), 8.17(\mathrm{~d}, 1 \mathrm{H}, J=8.9 \mathrm{~Hz}), 8.27(\mathrm{~d}, 1 \mathrm{H}, J=8.8 \mathrm{~Hz}), 8.55(\mathrm{~s}, 1 \mathrm{H}), 8.68(\mathrm{~s}, 1 \mathrm{H}), 9.57$ $\left(\mathrm{d}, 1 \mathrm{H}, J=7.4 \mathrm{~Hz}\right.$ ) ppm. ${ }^{13} \mathrm{C}$ NMR (DMSO- $\left.d_{6}\right) \delta: 14.7,58.7,61.5,65.6,125.2,126.2$, $128.3,129.4,130.1,130.3,130.6,132.7,134.0,134.6,166.0,166.8,170.4$ ppm. IR (neat) $v_{\max }: 3408,1831,1799,1710,1654 \mathrm{~cm}^{-1}$. Anal. $\left(\mathrm{C}_{17} \mathrm{H}_{15} \mathrm{NO}_{5}\right) \mathrm{C}, \mathrm{H}, \mathrm{N}$.

(S)-6-Methoxy- $\boldsymbol{N}$-(2-oxo-3-oxetanyl)naphthalene-2-carboxamide (71): White solid. Yield: $10 \%$ (0.035 g). $\mathrm{Mp} 205^{\circ} \mathrm{C}\left[\mathrm{CH}_{3} \mathrm{C}(\mathrm{O}) \mathrm{CH}_{3} /\right.$ petroleum ether $] .[\alpha]^{20}{ }_{\mathrm{D}}-17[c 0.08$, $\mathrm{CH}_{3} \mathrm{C}(\mathrm{O}) \mathrm{CH}_{3}$ ]. MS (EI) m/z: $271\left(\mathrm{M}^{+}\right), 171$ (100). $1 \mathrm{H} \mathrm{NMR}\left[\mathrm{CD}_{3} \mathrm{C}(\mathrm{O}) \mathrm{CD}_{3}\right] \delta: 3.95$ (s, 3H), 4.54-4.67 (m, 2H), 5.51-5.61 (m, 1H), $7.23(\mathrm{dd}, 1 \mathrm{H}, J=9.0,2.5 \mathrm{~Hz}), 7.38(\mathrm{~d}, 1 \mathrm{H}, J=2.5$

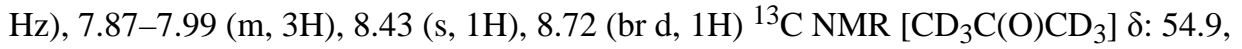
$58.9,65.1,105.7,119.7,124.4,127.1,127.8,127.9,128.1,130.5,136.7,159.4,169.4$ ppm. IR (Nujol) $v_{\max }: 3419,1825,1720,1627 \mathrm{~cm}^{-1}$. Anal. $\left(\mathrm{C}_{15} \mathrm{H}_{13} \mathrm{NO}_{4}\right) \mathrm{C}, \mathrm{H}, \mathrm{N}$.

(S)-(2-Oxo-3-oxetanylcarbamoyl)terephthalamic Acid Phenyl Ester (7m): White solid. Yield: $13 \%$ (0.053 g). Mp 222-226 ${ }^{\circ} \mathrm{C}$ dec from $150{ }^{\circ} \mathrm{C}\left(\mathrm{CHCl}_{3} / n\right.$-hexane). $[\alpha]^{20} \mathrm{D}-15.5[c$ $\left.0.09, \mathrm{CH}_{3} \mathrm{C}(\mathrm{O}) \mathrm{CH}_{3}\right]$. MS (EI) $m / z: 311\left(\mathrm{M}^{+}\right), 65(100) .{ }^{1} \mathrm{H}$ NMR $\left[\mathrm{CD}_{3} \mathrm{C}(\mathrm{O}) \mathrm{CD}_{3}\right] \delta: 4.56-$ $4.67(\mathrm{~m}, 2 \mathrm{H}), 5.54-5.63(\mathrm{~m}, 1 \mathrm{H}), 7.29-7.37(\mathrm{~m}, 3 \mathrm{H}), 7.45-7.54(\mathrm{~m}, 2 \mathrm{H}), 8.05-8.15(\mathrm{~m}, 2 \mathrm{H})$, 8.27-8.33 (m, 2H), 8.87 (br d, $1 \mathrm{H})$ ppm. ${ }^{13} \mathrm{C} \mathrm{NMR}\left[\mathrm{CD}_{3} \mathrm{C}(\mathrm{O}) \mathrm{CD}_{3}\right]$ \&: 58.8, 65.0, 121.8, 126.0, 127.7, 129.5, 130.1, 132.6, 137.6, 151.1, 163.9, 165.8, 168.9 ppm. IR (Nujol) $v_{\max }$ : $3304,1827,1731,1647 \mathrm{~cm}^{-1}$. Anal. $\left(\mathrm{C}_{17} \mathrm{H}_{13} \mathrm{NO}_{5}\right) \mathrm{C}, \mathrm{H}, \mathrm{N}$.

(S)-4-(Benzyloxy)- $N$-(2-oxo-3-oxetanyl)benzamide (7n): White solid. Yield: $61 \%(0.235$ g). Mp 205-208 ${ }^{\circ} \mathrm{C}$, decomposition with colour change and shrinkage starting from $170{ }^{\circ} \mathrm{C}$, sealed capillary tube $\left(\mathrm{CH}_{2} \mathrm{Cl}_{2} /\right.$ hexane). $[\alpha]^{20}{ }_{\mathrm{D}}-17.6(c 0.5, \mathrm{MeCN}) . \mathrm{MS}(\mathrm{EI}) \mathrm{m} / \mathrm{z}: 297\left(\mathrm{M}^{+}\right)$, 91 (100). ${ }^{1} \mathrm{H}$ NMR (DMSO-d $\left.{ }_{6}\right) \delta: 4.41-4.46(\mathrm{~m}, 2 \mathrm{H}), 5.17(\mathrm{~s}, 2 \mathrm{H}), 5.29-5.38(\mathrm{~m}, 1 \mathrm{H})$, 7.09-7.14 (m, 2H), 7.32-7.48 (m, 5H), 7.80-7.87 (m, 2H), 9.15 (d, 1H, J = 7.5 Hz) ppm. ${ }^{13} \mathrm{C}$ NMR (DMSO- $\left.d_{6}\right) \delta: 58.6,65.7,69.9,115.0,125.4,128.3,128.4,128.9,129.8$, 137.0, 161.7, 166.4, 170.7 ppm. IR (Nujol) $v_{\max }: 3380,1825,1637 \mathrm{~cm}^{-1}$. Anal.

$\left(\mathrm{C}_{17} \mathrm{H}_{15} \mathrm{NO}_{4}\right) \mathrm{C}, \mathrm{H}, \mathrm{N}$.

Synthesis of $(S)$-3-Hydroxy-2-(3-Phenylpropionylamino)propionic Acid (10).33: To a stirred solution of L-serine $(1.050 \mathrm{~g}, 10 \mathrm{mmol})$ in aqueous $2 \mathrm{~N} \mathrm{NaOH}(10 \mathrm{~mL})$, at $0{ }^{\circ} \mathrm{C}$, 3phenylpropionyl chloride (6a) $(1.855 \mathrm{~g}, 1.67 \mathrm{~mL}, 11 \mathrm{mmol})$ and aqueous $2 \mathrm{~N} \mathrm{NaOH} \mathrm{(10}$ $\mathrm{mL}$ ) were alternatively added in 8 portions. The mixture was stirred at $0{ }^{\circ} \mathrm{C}$ for further $4 \mathrm{~h}$, then acidified with $5 \mathrm{~N} \mathrm{HCl}$, filtered, and the filtrate extracted with EtOAc. The combined organic layers were dried $\left(\mathrm{Na}_{2} \mathrm{SO}_{4}\right)$ and concentrated. Purification of the residue by recrystallization gave 10 as off-white crystals. Yield: $40 \%(0.950 \mathrm{~g})$. Mp $127{ }^{\circ} \mathrm{C}(\mathrm{EtOAc})$. 
$[\alpha]^{20}{ }_{\mathrm{D}}+6.7\left(c\right.$ 0.36, MeOH). MS (EI) $m / z: 237\left(\mathrm{M}^{+}\right), 91(100) .{ }^{1} \mathrm{H}$ NMR $\left[\mathrm{CD}_{3} \mathrm{C}(\mathrm{O}) \mathrm{CD}_{3}\right] \delta$ : 2.54-2.62 (m, 2H), 2.88-2.97 (m, 2H), $3.77\left(\mathrm{dd}, 1 \mathrm{H}, J_{1}=11.0 \mathrm{~Hz}, J_{2}=4.2 \mathrm{~Hz}\right), 3.91(\mathrm{dd}$, $\left.1 \mathrm{H}, J_{1}=11.0 \mathrm{~Hz}, J_{2}=4.5 \mathrm{~Hz}\right), 4.51(\mathrm{~m}, 1 \mathrm{H}), 7.16-7.31(\mathrm{~m}, 6 \mathrm{H}) \mathrm{ppm} .{ }^{13} \mathrm{C} \mathrm{NMR}$ $\left[\mathrm{CD}_{3} \mathrm{C}(\mathrm{O}) \mathrm{CD}_{3}\right]$ 8: 31.3, 37.3, 54.5, 62.2, 125.8, 128.2, 128.3, 141.6, 171.2, $171.7 \mathrm{ppm}$. IR (Nujol) $v_{\max }: 3303,1730,1715,1647,1625 \mathrm{~cm}^{-1}$. Anal. $\left(\mathrm{C}_{12} \mathrm{H}_{15} \mathrm{NO}_{4}\right) \mathrm{C}, \mathrm{H}, \mathrm{N}$.

General Procedure for the Synthesis of (S)- $\mathrm{N}$-(2-Oxotetrahydrofuran-3yl)amides (11a,j) - To a stirred suspension of $(S)$-3-aminodihydrofuran-2-one hydrobromide $(0.501 \mathrm{~g}, 2.75 \mathrm{mmol})$ in dry $\mathrm{CH}_{2} \mathrm{Cl}_{2}(7 \mathrm{~mL})$, at $0{ }^{\circ} \mathrm{C}$ and under $\mathrm{N}_{2}$ atmosphere, $\mathrm{Et}_{3} \mathrm{~N}(0.972 \mathrm{~g}, 1.35 \mathrm{~mL}, 9.68 \mathrm{mmol})$ was added; the salt was dissolved at first, then a white precipitate was produced. The opportune acid chloride $\mathbf{6 a}, \mathbf{j}(5.38 \mathrm{mmol})$ was added dropwise to the mixture, which was stirred at $0{ }^{\circ} \mathrm{C}$ for $0.5 \mathrm{~h}$ and at room temperature for $3 \mathrm{~h}$, added of $\mathrm{CH}_{3} \mathrm{C}(\mathrm{O}) \mathrm{CH}_{3}$ and filtered, then the filtrate was concentrated. Purification of the residue by column chromatography (cyclohexane/EtOAc 7:3 to EtOAc) and recrystallization gave 11a,j.

(S)- $\mathrm{N}$-(2-Oxotetrahydrofuran-3-yl)-3-phenylpropionamide (11a).34: White solid. Yield: $86 \%\left(0.550\right.$ g). $\mathrm{Mp} 149-150{ }^{\circ} \mathrm{C}\left[\mathrm{CH}_{3} \mathrm{C}(\mathrm{O}) \mathrm{CH}_{3} /\right.$ petroleum ether] (lit. 150.0-150.8)56. $[\alpha]^{20}{ }_{\mathrm{D}}$ -23.6 (c 0.55, MeCN). MS (EI) $m / z: 233\left(\mathrm{M}^{+}\right), 91(100) .{ }^{1} \mathrm{H}$ NMR $\left[\mathrm{CD}_{3} \mathrm{C}(\mathrm{O}) \mathrm{CD}_{3}\right] \delta: 2.10$ $2.31(\mathrm{~m}, 1 \mathrm{H}), 2.47-2.62(\mathrm{~m}, 3 \mathrm{H}), 2.82-2.95(\mathrm{~m}, 2 \mathrm{H}), 4.21-4.44(\mathrm{~m}, 2 \mathrm{H}), 4.56-4.70(\mathrm{~m}, 1 \mathrm{H})$, 7.16-7.28 (m, 5H), 7.52 (br s, $1 \mathrm{H}) \mathrm{ppm} .{ }^{13} \mathrm{C} \mathrm{NMR}\left[\mathrm{CD}_{3} \mathrm{C}(\mathrm{O}) \mathrm{CD}_{3}\right]$ 8: 28.9, 31.2, 37.2, 48.3, $65.1,125.9,128.3,141.4,171.5,174.7 \mathrm{ppm}$. IR (Nujol) $v_{\max }: 3294,1776,1644 \mathrm{~cm}^{-1}$. Anal. $\left(\mathrm{C}_{13} \mathrm{H}_{15} \mathrm{NO}_{3}\right) \mathrm{C}, \mathrm{H}, \mathrm{N}$.

(S)- $N$-(2-Oxotetrahydrofuran-3-yl)-2-naphthamide $(\mathbf{1 1 j})$ : White fluffy needles. Yield: $87 \%(0.610 \mathrm{~g})$. Mp $221-222{ }^{\circ} \mathrm{C}\left[\mathrm{CH}_{3} \mathrm{C}(\mathrm{O}) \mathrm{CH}_{3} /\right.$ petroleum ether]. $[\alpha]^{20}{ }_{\mathrm{D}}-29.2(c$ 0.4, $\mathrm{MeCN})$. MS (EI) m/z: $255\left(\mathrm{M}^{+}\right), 155(100) .{ }^{1} \mathrm{H}$ NMR $\left[\mathrm{CD}_{3} \mathrm{C}(\mathrm{O}) \mathrm{CD}_{3}\right] \delta: 2.40-2.78(\mathrm{~m}, 2 \mathrm{H})$, 4.32-4.56 (m, 2H), 4.89-5.03 (m, 1H), 7.56-7.66 (m, 2H), 7.96-8.04 (m, 4H), 8.37 (br s, $1 \mathrm{H}), 8.50(\mathrm{~s}, 1 \mathrm{H}) \mathrm{ppm} .{ }^{13} \mathrm{C} \mathrm{NMR}\left[\mathrm{CD}_{3} \mathrm{C}(\mathrm{O}) \mathrm{CD}_{3}\right] \delta: 28.7,48.8,65.2,123.9,126.7,127.6$, $127.7,128.1,128.9,131.4,132.7,134.9,166.4,174.7 \mathrm{ppm}$. IR (Nujol) $v_{\max }: 3357,1760$, $1654 \mathrm{~cm}^{-1}$. Anal. $\left(\mathrm{C}_{15} \mathrm{H}_{13} \mathrm{NO}_{3}\right) \mathrm{C}, \mathrm{H}, \mathrm{N}$.

Synthesis of $\mathrm{N}$-Cyclobutyl-3-phenylpropionamide (12).23: To a stirred solution of c$\mathrm{C}_{4} \mathrm{H}_{7} \mathrm{NH}_{2}(0.213 \mathrm{~g}, 0.26 \mathrm{~mL}, 3 \mathrm{mmol})$ and $\mathrm{Et}_{3} \mathrm{~N}(0.404 \mathrm{~g}, 0.56 \mathrm{~mL}, 4 \mathrm{mmol})$ in dry $\mathrm{CH}_{2} \mathrm{Cl}_{2}$ $(15 \mathrm{~mL})$, at $0{ }^{\circ} \mathrm{C}$ and under $\mathrm{N}_{2}$ atmosphere, $6 \mathbf{a}(0.523 \mathrm{~g}, 0.46 \mathrm{~mL}, 3.1 \mathrm{mmol})$ was added dropwise. The solution was stirred at room temperature for $3 \mathrm{~h}$ and concentrated. Purification of the residue by column chromatography (cyclohexane/EtOAc 7:3) and recrystallization gave 12 as white needles. Yield: $82 \%(0.500 \mathrm{~g}) . \mathrm{Mp} 109-110{ }^{\circ} \mathrm{C}\left(\mathrm{Et}_{2} \mathrm{O} /\right.$ petroleum ether). MS (EI) m/z: $204\left(\mathrm{M}^{+}\right), 174(100) .{ }^{1} \mathrm{H}$ NMR $\left(\mathrm{CDCl}_{3}\right) \delta: 1.68-1.85(\mathrm{~m}$, $4 \mathrm{H}), 2.18-2.36(\mathrm{~m}, 2 \mathrm{H}), 2.42(\mathrm{t}, 2 \mathrm{H}, J=8.0 \mathrm{~Hz}), 2.96(\mathrm{t}, 2 \mathrm{H}, J=8.0 \mathrm{~Hz}), 4.28-4.48(\mathrm{~m}$, $1 \mathrm{H}), 5.50(\mathrm{br} \mathrm{s}, 1 \mathrm{H}), 7.16-7.33(\mathrm{~m}, 5 \mathrm{H}) \mathrm{ppm} .{ }^{13} \mathrm{C} \mathrm{NMR}\left(\mathrm{CDCl}_{3}\right) \delta: 15.0,31.2,31.8,38.5$, $44.6,126.2,128.4,128.5,140.9,171.2 \mathrm{ppm}$. IR (Nujol) $v_{\max }: 3297,1642,1544 \mathrm{~cm}^{-1}$. Anal. $\left(\mathrm{C}_{13} \mathrm{H}_{17} \mathrm{NO}\right) \mathrm{C}, \mathrm{H}, \mathrm{N}$.

Synthesis of 3-Phenylpropionamide (14).35: To a stirred solution of 3-phenylpropionitrile (13) $(1.310 \mathrm{~g}, 1.3 \mathrm{~mL}, 10 \mathrm{mmol})$ in aqueous $60 \%$ tert-butanol $(14.5 \mathrm{~mL})$, aqueous $1 \mathrm{~N}$ $\mathrm{NaOH}(10.8 \mathrm{~mL})$ and aqueous $30 \% \mathrm{H}_{2} \mathrm{O}_{2}(1.8 \mathrm{~mL})$ were added. The mixture was stirred at room temperature for $3 \mathrm{~h}$, concentrated, acidified with $1 \mathrm{~N} \mathrm{HCl}$ and extracted with $\mathrm{CH}_{2} \mathrm{Cl}_{2}$. The combined organic layers were washed with brine, dried $\left(\mathrm{Na}_{2} \mathrm{SO}_{4}\right)$ and concentrated. Purification of the residue by column chromatography (cyclohexane/EtOAc 1:1 to EtOAc) and trituration with hexane gave $\mathbf{1 4}$ as a white solid. Yield: 50\% (0.750 g). Mp, MS, ${ }^{1} \mathrm{H}$ NMR and IR are according to the literature.57 
Synthesis of $\mathrm{N}$-(2-Oxocyclobutyl)-3-phenylpropionamide (15).23: To a stirred solution of $14(0.067 \mathrm{~g}, 0.45 \mathrm{mmol})$ in dry THF $(5 \mathrm{~mL})$ and ethereal $2 \mathrm{~N} \mathrm{HCl}(5 \mathrm{~mL})$, at $0{ }^{\circ} \mathrm{C}$ and under $\mathrm{N}_{2}$ atmosphere, 1,2-bis(trimethylsilanyloxy)cyclobutene $(0.099 \mathrm{~g}, 0.11 \mathrm{~mL}, 0.43 \mathrm{mmol}$ ) was added. The solution was stirred at reflux for $3 \mathrm{~h}$, then concentrated. Purification of the residue by column chromatography (cyclohexane/EtOAc 6:4 to 3:7) and trituration of the colorless oil previously obtained gave $\mathbf{1 5}$ as an off-white solid. Yield: $70 \%(0.065 \mathrm{~g}) . \mathrm{Mp}$ 70-73 ${ }^{\circ} \mathrm{C}$ (hexane). MS (EI) $\mathrm{m} / z: 217\left(\mathrm{M}^{+}\right), 91(100) .{ }^{1} \mathrm{H} \mathrm{NMR}\left(\mathrm{CDCl}_{3}\right) \delta: 1.87-2.06(\mathrm{~m}$, $1 \mathrm{H}), 2.32-2.58(\mathrm{~m}, 3 \mathrm{H}), 2.90-3.00(\mathrm{~m}, 4 \mathrm{H}), 4.86-4.99(\mathrm{~m}, 1 \mathrm{H}), 5.91$ (br d, $1 \mathrm{H}, J=6.4 \mathrm{~Hz}$ ), 7.18-7.35 (m, 5H) ppm. ${ }^{13} \mathrm{C}$ NMR $\left(\mathrm{CDCl}_{3}\right) \delta: 19.7,31.4,37.8,42.1,64.1,126.3,128.3$, 128.6, 140.5, 171.8, $205.3 \mathrm{ppm}$. IR (Nujol) $v_{\max }: 3287,1784,1646 \mathrm{~cm}^{-1}$. Anal. $\left(\mathrm{C}_{13} \mathrm{H}_{15} \mathrm{NO}_{2}\right) \mathrm{C}, \mathrm{H}, \mathrm{N}$.

Synthesis of (2S,3R)-2-tert-Butoxycarbonylamino-3-hydroxybutyric Acid (17a).37: To a stirred solution of L-threonine (16a) $(1.001 \mathrm{~g}, 8.4 \mathrm{mmol})$ and $\mathrm{NaHCO}_{3}(1.092 \mathrm{~g}, 13 \mathrm{mmol})$ in $\mathrm{H}_{2} \mathrm{O}(17 \mathrm{~mL}), \mathrm{MeOH}(17 \mathrm{~mL})$ and $\mathrm{Boc}_{2} \mathrm{O}(2.684 \mathrm{~g}, 12.3 \mathrm{mmol})$ were added. The mixture was stirred at room temperature for $36 \mathrm{~h}$, concentrated, acidified with $1 \% \mathrm{HCl}$ until $\mathrm{pH} 2$ and extracted with EtOAc. The combined organic layers were washed with brine, dried $\left(\mathrm{Na}_{2} \mathrm{SO}_{4}\right)$ and concentrated to give 17a as a colorless oil. Yield: $87 \%(1.600 \mathrm{~g})$. MS (EI) $\mathrm{m} /$ $z: 220\left(\mathrm{M}^{+}\right), 101(100) .{ }^{1} \mathrm{H}$ NMR $\left(\mathrm{CDCl}_{3}\right) \delta: 1.25(\mathrm{~d}, 3 \mathrm{H}, J=6.1 \mathrm{~Hz}), 1.44(\mathrm{~s}, 9 \mathrm{H}), 4.25-$ $4.41(\mathrm{~m}, 2 \mathrm{H}), 5.75(\mathrm{~d}, 1 \mathrm{H}, J=9.2 \mathrm{~Hz}), 7.35$ (br s, 2H) ppm.

Synthesis of (2R,3S)-2-tert-Butoxycarbonylamino-3-hydroxybutyric Acid (17b).38: The same protocol applied to D-threonine (16b) gave 17b as a colorless oil. Yield: 95\% (1.748 g). MS (EI) and ${ }^{1} \mathrm{H}$ NMR data are identical to those of $\mathbf{1 7} \mathbf{a}$.

Synthesis of (2R,3S)-2-Methyl-4-oxo-3-oxetanylcarbamic Acid tert-Butyl Ester (18a). 40: To a stirred suspension of $N$-Boc-L-threonine (17a) $(1.600 \mathrm{~g}, 7.3 \mathrm{mmol})$ in dry $\mathrm{CH}_{2} \mathrm{Cl}_{2}$ $(150 \mathrm{~mL})$, at $0{ }^{\circ} \mathrm{C}$ and under $\mathrm{N}_{2}$ atmosphere, $\mathrm{Et}_{3} \mathrm{~N}(2.21 \mathrm{~g}, 3.05 \mathrm{~mL}, 21.9 \mathrm{mmol})$ and BOP reagent $(3.892 \mathrm{~g}, 8.8 \mathrm{mmol})$ were added. The mixture was stirred at room temperature for 3 $\mathrm{h}$, then concentrated. Purification of the residue by column chromatography (cyclohexane/ EtOAc 1:1) and recrystallization gave 18a as an off-white solid. Yield: 63\% (0.930 g). Mp $141-143{ }^{\circ} \mathrm{C}\left(\mathrm{CHCl}_{3} /\right.$ hexane) (lit. $\left.141-142{ }^{\circ} \mathrm{C}\right) 58 .[\alpha]_{\mathrm{D}} 20+25.4(c 0.7, \mathrm{MeOH})[$ lit. $+20.4(c$ $\left.\left.1.16, \mathrm{CHCl}_{3}\right)\right] .58 \mathrm{MS}(\mathrm{EI}) \mathrm{m} / z: 202\left(\mathrm{M}^{+1}\right), 57(100) .{ }^{1} \mathrm{H} \mathrm{NMR}\left(\mathrm{CDCl}_{3}\right) \delta: 1.45-1.48(\mathrm{~m}$, $12 \mathrm{H}$ ), $4.80-4.93(\mathrm{~m}, 1 \mathrm{H}), 5.27$ (br d, 1H), 5.40-5.47 (m, 1H) ppm. IR (nujol) $v_{\max }: 3353$, $1830,1701 \mathrm{~cm}^{-1}$.

Synthesis of (2S,3R)-2-Methyl-4-oxo-3-oxetanylcarbamic Acid tert-Butyl Ester (18b): The same protocol applied to $17 \mathrm{~b}$ gave $18 \mathrm{~b}$ as a white solid. Yield $70 \%(0.510 \mathrm{~g})$. Mp 140 $141{ }^{\circ} \mathrm{C}\left(\mathrm{CHCl}_{3} /\right.$ hexane). $[\alpha]^{20}{ }_{\mathrm{D}}-26.8(c 0.6, \mathrm{MeOH})$. MS (EI) $m / z: 202\left(\mathrm{M}^{+1}\right), 57(100) .{ }^{1} \mathrm{H}$ NMR $\left(\mathrm{CDCl}_{3}\right) \delta: 1.45-1.48(\mathrm{~m}, 12 \mathrm{H}), 4.80-4.93(\mathrm{~m}, 1 \mathrm{H}), 5.27$ (br d, 1H), 5.40-5.47 (m, 1H) ppm. IR (nujol) $v_{\max }: 3352,1829,1713 \mathrm{~cm}^{-1}$.

Synthesis of (3S,4R)-2-Methyl-4-oxo-3-oxetanylammonium Toluene-4-sulfonate (19a). 41: To a stirred mixture of $18 \mathrm{a}(0.402 \mathrm{~g}, 2 \mathrm{mmol})$ and dry $p$-TsOH $(0.406 \mathrm{~g}, 2.13 \mathrm{mmol})$, at $0^{\circ} \mathrm{C}$ and under $\mathrm{N}_{2}$ atmosphere, $\mathrm{CF}_{3} \mathrm{COOH}(4.5 \mathrm{~mL})$ was added dropwise in the course of 10 min. The solution was stirred at $0{ }^{\circ} \mathrm{C}$ for $0.25 \mathrm{~h}$ and concentrated at a temperature below 30 ${ }^{\circ} \mathrm{C}$. The oily residue was kept under vacuum for $1 \mathrm{~h}$ and added of dry $\mathrm{Et}_{2} \mathrm{O}$. Purification of the resulting solid by repeated trituration with dry $\mathrm{Et}_{2} \mathrm{O}$ gave 19a as an off-white solid, which starts to decompose from $120^{\circ} \mathrm{C}$ [lit. $120^{\circ} \mathrm{C}$ dec (EtOAc/hexane)].41 Yield: $92 \%$ $(0.500 \mathrm{~g}) .{ }^{1} \mathrm{H}$ NMR and IR are according to the literature.41

Synthesis of $(3 R, 4 S)$-2-Methyl-4-oxo-3-oxetanylammonium Toluene-4-sulfonate (19b): The same protocol applied to $\mathbf{1 8 b}$ afforded $\mathbf{1 9 b}$ as an off-white solid which starts to 
decompose from $120{ }^{\circ} \mathrm{C}$. Yield: $77 \%(0.420 \mathrm{~g}) .{ }^{1} \mathrm{H}$ NMR (DMSO- $\left.d_{6}\right) \delta: 1.51(\mathrm{~d}, 3 \mathrm{H}, J=6.4$ $\mathrm{Hz}), 2.28(\mathrm{~s}, 3 \mathrm{H}), 4.97(\mathrm{~m}, 1 \mathrm{H}), 5.16(\mathrm{~d}, 1 \mathrm{H}, J=6.2 \mathrm{~Hz}), 7.12(\mathrm{~d}, 2 \mathrm{H}, J=7.9 \mathrm{~Hz}), 7.47(\mathrm{~d}$, $2 \mathrm{H}, J=8.2 \mathrm{~Hz}$ ), 8.90 (br s, 3H) ppm. IR (Nujol) $v_{\max }: 3392,3162,1838,1717 \mathrm{~cm}^{-1}$.

Synthesis of (2R,3S)- $N$-(2-Methyl-4-oxo-3-oxetanyl)-3-phenylpropionamide (20a): To a stirred mixture of $19 a(0.402 \mathrm{~g}, 1.47 \mathrm{mmol})$ in dry $\mathrm{CH}_{2} \mathrm{Cl}_{2}(8 \mathrm{~mL})$, at $0{ }^{\circ} \mathrm{C}$ and under $\mathrm{N}_{2}$ atmosphere, $\mathrm{Et}_{3} \mathrm{~N}(0.591 \mathrm{~g}, 0.81 \mathrm{~mL}, 5.84 \mathrm{mmol})$ was added dropwise and, successively, 3phenylpropionyl chloride $(6 \mathbf{6 a})(0.372 \mathrm{~g}, 0.33 \mathrm{~mL}, 2.21 \mathrm{mmol})$. The mixture was reacted at 0 ${ }^{\circ} \mathrm{C}$ for $0.5 \mathrm{~h}$ and at room temperature for $3 \mathrm{~h}$, then concentrated. Purification of the residue by column chromatography (cyclohexane/EtOAc 7:3 to EtOAc) and recrystallization gave 20a as a white solid. Yield: $53 \%(0.180 \mathrm{~g})$. $\mathrm{Mp} 115-116^{\circ} \mathrm{C}\left(\mathrm{CHCl}_{3} / n\right.$-hexane). $[\alpha]^{20} \mathrm{D}+32.8$ (c 0.5, MeOH). MS (EI) $m / z: 233\left(\mathrm{M}^{+}, 100\right) .{ }^{1} \mathrm{H} \mathrm{NMR}\left(\mathrm{CDCl}_{3}\right) \delta: 1.23(\mathrm{~d}, 3 \mathrm{H}, J=6.3 \mathrm{~Hz})$, 2.55-2.64 (m, 2H), 2.99 (t, $2 \mathrm{H}, J=7.5 \mathrm{~Hz}), 4.78-4.90(\mathrm{~m}, 1 \mathrm{H}), 5.59$ (dd, $1 \mathrm{H}, J=7.9,6.0$ $\mathrm{Hz}), 6.36(\mathrm{br} \mathrm{d}, 1 \mathrm{H}, J=7.3 \mathrm{~Hz}), 7.18-7.30(\mathrm{~m}, 5 \mathrm{H}) \mathrm{ppm} .{ }^{13} \mathrm{C} \mathrm{NMR}\left(\mathrm{CDCl}_{3}\right) \delta: 14.8,31.3$, $37.6,58.7,74.9,126.6,128.3,128.7,140.0,169.3,172.1 \mathrm{ppm}$. IR (Nujol) $v_{\max }: 3282,1827$, $1656 \mathrm{~cm}^{-1}$. Anal. $\left(\mathrm{C}_{13} \mathrm{H}_{15} \mathrm{NO}_{3}\right) \mathrm{C}, \mathrm{H}, \mathrm{N}$.

Synthesis of (2S,3R)- $N$-(2-Methyl-4-oxo-3-oxetanyl)-3-phenylpropionamide (20b): The same protocol procedure applied to $\mathbf{1 9 b}$ gave $\mathbf{2 0 b}$ as a white fluffy solid. Yield: $58 \%$ (0.199 g). Mp $117-119^{\circ} \mathrm{C}\left(\mathrm{CHCl}_{3} / n\right.$-hexane). $[\alpha]^{20}{ }_{\mathrm{D}}-33.1$ ( $c$ 0.55, MeOH). MS (EI) $m / z: 233$ $\left(\mathrm{M}^{+}\right), 91(100) .{ }^{1} \mathrm{H} \mathrm{NMR}\left(\mathrm{CDCl}_{3}\right) \delta: 1.23(\mathrm{~d}, 3 \mathrm{H}, J=6.3 \mathrm{~Hz}), 2.55-2.64(\mathrm{~m}, 2 \mathrm{H}), 2.99(\mathrm{t}$, $2 \mathrm{H}, J=7.5 \mathrm{~Hz}), 4.78-4.90(\mathrm{~m}, 1 \mathrm{H}), 5.59(\mathrm{dd}, 1 \mathrm{H}, J=7.9,6.0 \mathrm{~Hz}), 6.16(\mathrm{br} \mathrm{d}, 1 \mathrm{H}, J=7.3$ $\mathrm{Hz}), 7.19-7.27(\mathrm{~m}, 5 \mathrm{H}) \mathrm{ppm} .{ }^{13} \mathrm{C} \mathrm{NMR}\left(\mathrm{CDCl}_{3}\right) \delta: 14.8,31.3,37.6,58.7,74.8,126.5$, 128.3, 128.7, 140.0, 169.1, $172.0 \mathrm{ppm}$. IR (Nujol) $v_{\max }: 3282,1827,1655 \mathrm{~cm}^{-1}$. Anal. $\left(\mathrm{C}_{13} \mathrm{H}_{15} \mathrm{NO}_{3}\right) \mathrm{C}, \mathrm{H}, \mathrm{N}$.

Synthesis of 2-(Bromomethyl)-6-phenylhexanoic Acid (22): To a stirred solution of 2methylene-6-phenylhexanoic acid (21) $(0.239 \mathrm{~g}, 1.17 \mathrm{mmol})$ in $\mathrm{CH}_{2} \mathrm{Cl}_{2}(3 \mathrm{~mL})$, at $0{ }^{\circ} \mathrm{C}, 5.7$ $\mathrm{M} \mathrm{HBr}$ in $\mathrm{CH}_{3} \mathrm{COOH}(0.6 \mathrm{~mL}, 3.42 \mathrm{mmol})$ was added dropwise. The mixture was stirred at $0{ }^{\circ} \mathrm{C}$ for $3 \mathrm{~h}$ and at room temperature for $36 \mathrm{~h}$. A further amount of $5.7 \mathrm{M} \mathrm{HBr}$ in $\mathrm{CH}_{3} \mathrm{COOH}(0.2 \mathrm{~mL}, 1.14 \mathrm{mmol})$ was added and the mixture stirred for further $16 \mathrm{~h}$. The mixture was poured onto ice $\mathrm{H}_{2} \mathrm{O}(250 \mathrm{~mL})$ and extracted with $\mathrm{Et}_{2} \mathrm{O}$. The combined organic layers were washed with brine, dried $\left(\mathrm{Na}_{2} \mathrm{SO}_{4}\right)$ and concentrated. Purification of the residue by column chromatography (cyclohexane/EtOAc 8:2 to 1:1 to EtOAc) gave 22 as a colorless oil. Yield: $48 \%$ (0.160 g). MS (EI) $\mathrm{m} / z: 285 / 287\left(\mathrm{M}^{+}\right), 91(100) .{ }^{1} \mathrm{H}$ NMR $\left(\mathrm{CDCl}_{3}\right) \delta: 1.38-$ $1.49(\mathrm{~m}, 2 \mathrm{H}), 1.64-1.76(\mathrm{~m}, 4 \mathrm{H}), 2.64(\mathrm{t}, 2 \mathrm{H}, J=7.8 \mathrm{~Hz}), 2.78-2.92(\mathrm{~m}, 1 \mathrm{H}), 3.45-3.63(\mathrm{~m}$, 2H), 7.16-7.32 (m, 5H) ppm. IR (neat) $v_{\max }: 3026,2931,2858,1709 \mathrm{~cm}^{-1}$.

Synthesis of rac-3-(4-Phenylbutyl)oxetan-2-one (23): To a stirred suspension of 22 (0.148 $\mathrm{g}, 0.52 \mathrm{mmol})$ in aqueous $1 \mathrm{~N} \mathrm{NaOH}(0.60 \mathrm{~mL}, 0.6 \mathrm{mmol}), \mathrm{CHCl}_{3}(2 \mathrm{~mL})$ was added. The mixture was stirred vigorously at room temperature for $10 \mathrm{~min} . \mathrm{H}_{2} \mathrm{O}(1 \mathrm{~mL})$ and $1 \mathrm{~N} \mathrm{NaOH}$ $(0.50 \mathrm{~mL})$ were added, the organic layer was separated and $\mathrm{CHCl}_{3}(5 \mathrm{~mL})$ was added to the aqueous layer. The mixture was stirred for $1 \mathrm{~h}$ and the organic layer separated. Further amount of $\mathrm{CHCl}_{3}(5 \mathrm{~mL})$ was added to the aqueous layer, the mixture was stirred for $1 \mathrm{~h}$ and organic layer separated. The combined organic layers were dried $\left(\mathrm{Na}_{2} \mathrm{SO}_{4}\right)$ and concentrated. Purification of the residue by column chromatography (cyclohexane/EtOAc 8:2) gave 23 as a light brown oil. Yield: 29\% (0.030 g). MS (EI) $\mathrm{m} / z: 204\left(\mathrm{M}^{+}\right), 91(100) .{ }^{1} \mathrm{H}$ $\operatorname{NMR}\left(\mathrm{CDCl}_{3}\right) \delta: 1.38-2.01(\mathrm{~m}, 6 \mathrm{H}), 2.64(\mathrm{t}, 2 \mathrm{H}, J=7.8 \mathrm{~Hz}), 3.64-3.77(\mathrm{~m}, 1 \mathrm{H}), 4.00(\mathrm{t}$, $1 \mathrm{H}, J=5.0 \mathrm{~Hz}), 4.36\left(\mathrm{dd}, 1 \mathrm{H}, J_{l}=5.1 \mathrm{~Hz}, J_{2}=6.3 \mathrm{~Hz}\right), 7.15-7.29(\mathrm{~m}, 5 \mathrm{H}) \mathrm{ppm} .{ }^{13} \mathrm{C} \mathrm{NMR}$ $\left(\mathrm{CDCl}_{3}\right) \delta: 26.4,28.0,31.0,35.6,52.0,65.0,125.9,128.3,128.4,142.0,171.7 \mathrm{ppm}$. IR (neat) $v_{\max }: 3026,2931,2859,1821 \mathrm{~cm}^{-1}$. Anal. $\left(\mathrm{C}_{13} \mathrm{H}_{16} \mathrm{O}_{2}\right) \mathrm{C}, \mathrm{H}$. 
Synthesis of Biphenyl-3-carboxylic Acid (9g).. : $:$ To a stirred solution of biphenyl-3carbaldehyde $(0.601 \mathrm{~g}, 3.3 \mathrm{mmol})$, the ${ }^{1} \mathrm{H}$ NMR of which is according to the literature,59 in $\mathrm{CH}_{3} \mathrm{C}(\mathrm{O}) \mathrm{CH}_{3}(46 \mathrm{~mL}), \mathrm{KMnO}_{4}(1.012 \mathrm{~g}, 6.4 \mathrm{mmol})$ in $\mathrm{H}_{2} \mathrm{O}(32 \mathrm{~mL})$ was added. The mixture was stirred at room temperature for $5 \mathrm{~h}$, concentrated, added of $\mathrm{CH}_{2} \mathrm{Cl}_{2} / \mathrm{MeOH}$ 9:1, filtered, and the filtrate concentrated. Purification of the residue by column chromatography $\left(\mathrm{CH}_{2} \mathrm{Cl}_{2} / \mathrm{MeOH} 9: 1\right)$ gave $9 \mathrm{~g}$ as a white solid. Yield: 60\% (0.380 g). Mp, MS and ${ }^{1} \mathrm{H}$ NMR data are according to the literature.60

Synthesis of Naphthalene-2,6-dicarboxylic Acid Monoethyl Ester (9k).45: A suspension of naphthalene-2,6-dicarboxylic acid (26) $(1.500 \mathrm{~g}, 6.94 \mathrm{mmol}), \mathrm{Et}_{3} \mathrm{~N}(1.404 \mathrm{~g}, 1.93 \mathrm{~mL}$, $13.88 \mathrm{mmol})$ and $\mathrm{EtBr}(0.907 \mathrm{~g}, 0.62 \mathrm{~mL}, 8.33 \mathrm{mmol})$ in dry DMF $(10 \mathrm{~mL})$, under $\mathrm{N}_{2}$ atmosphere, was stirred at $80{ }^{\circ} \mathrm{C}$ for $4 \mathrm{~h}$. The mixture was cooled to room temperature, diluted with $\mathrm{H}_{2} \mathrm{O}$, then acidified with $2 \mathrm{~N} \mathrm{HCl}$; the precipitate was filtered and the solid was washed with $\mathrm{H}_{2} \mathrm{O}$, and dried. Purification of the solid by column chromatography $\left(\mathrm{CH}_{2} \mathrm{Cl}_{2} /\right.$ $\mathrm{MeOH} 9: 1)$ gave 9k as a white solid. Yield: $32 \%(0.540 \mathrm{~g})$. Mp $233-237^{\circ} \mathrm{C}$. MS (EI) $\mathrm{m} / \mathrm{z}$ : $244\left(\mathrm{M}^{+}\right), 115(100) .{ }^{1} \mathrm{H}$ NMR [DMSO- $\left.d_{6}\right] \delta: 1.37(\mathrm{t}, 3 \mathrm{H}, J=7.1 \mathrm{~Hz}), 4.39$ (q, 2H, $J=7.1$ $\mathrm{Hz}), 8.01-8.07(\mathrm{~m}, 2 \mathrm{H}), 8.23(\mathrm{~d}, 2 \mathrm{H}, J=8.5 \mathrm{~Hz}), 8.66(\mathrm{~d}, 2 \mathrm{H}, J=4.7 \mathrm{~Hz}), 13.11(\mathrm{br} \mathrm{s}, 1 \mathrm{H})$ ppm. IR (Nujol) $v_{\max }: 3389,1705,1680 \mathrm{~cm}^{-1}$.

Synthesis of Terephthalic Acid Monophenyl Ester (9m).46: To a stirred solution of terephthaloyl dichloride (27) (3.490 g, $17.2 \mathrm{mmol})$ in $\mathrm{MeCN}(60 \mathrm{~mL})$, phenol (1.619 g, 17.2 $\mathrm{mmol})$ and $\mathrm{Et}_{3} \mathrm{~N}(3.491 \mathrm{~g}, 4.81 \mathrm{~mL}, 34.5 \mathrm{mmol})$ were added. The mixture was stirred at room temperature for $4 \mathrm{~h}$, then an aqueous solution of $2 \mathrm{~N} \mathrm{Na}_{2} \mathrm{CO}_{3}(80 \mathrm{~mL})$ was added and the mixture was stirred again for $15 \mathrm{~h}$, then acidified with $2 \mathrm{~N} \mathrm{HCl}$ and filtered. Purification of the solid by column chromatography $\left(\mathrm{CH}_{2} \mathrm{Cl}_{2} / \mathrm{MeOH} 9: 1\right.$ to $\mathrm{CH}_{2} \mathrm{Cl}_{2} / \mathrm{MeOH} / \mathrm{CH}_{3} \mathrm{COOH}$ 9:1.9:0.1) and recrystallization gave $\mathbf{9 m}$ as a white solid. Yield: $16 \%(0.666 \mathrm{~g})$. Mp 230-235 ${ }^{\circ} \mathrm{C}(\mathrm{EtOH})$ [the sample was heated so as to raise its temperature of $20^{\circ} \mathrm{C} / \mathrm{min}$; when heated more slowly $\left(3{ }^{\circ} \mathrm{C} / \mathrm{min}\right)$, it tends to decompose with colour and volume change, instead of melting] [lit. 238-240 ( $\left.\left.\mathrm{H}_{2} \mathrm{O} / \mathrm{EtOH}\right)\right] 61$. MS (EI) $\mathrm{m} / z: 242\left(\mathrm{M}^{+}\right), 65$ (100). IR (Nujol) $v_{\max }$ : $1739,1686 \mathrm{~cm}^{-1} .{ }^{1} \mathrm{H}$ NMR is according to the literature.62

Synthesis of 4-Benzyloxybenzoic acid (9n).49: MS (EI) m/z: $228\left(\mathrm{M}^{+}, 100\right)$. Pf, ${ }^{1} \mathrm{H}$ NMR and IR are according to the literature.50

\section{(b) Pharmacology}

NAAA assay-Recombinant NAAA, expressed as described below, was incubated at 37 ${ }^{\circ} \mathrm{C}$ for $30 \mathrm{~min}$ in $0.2 \mathrm{~mL}$ of sodium hydrogen phosphate buffer $(50 \mathrm{mM}, \mathrm{pH} 5.0)$ containing $0.1 \%$ Triton X-100, $3 \mathrm{mM}$ dithiothreitol (DTT) and $50 \mu \mathrm{M}$ heptadecenoylethanolamide as substrate. The reaction was terminated by the addition of $0.2 \mathrm{~mL}$ cold methanol containing 1 $\mathrm{nmol}$ of heptadecanoic acid (NuChek Prep, Elysian, MN). Samples were analyzed by liquid chromatography/mass spectrometry (LC/MS). Heptadecenoic and heptadecanoic acids were eluted on an XDB Eclipse C18 column isocratically at $2.2 \mathrm{~mL} / \mathrm{min}$ for 1 min with a solvent mixture of $95 \%$ methanol and 5\% water, both containing $0.25 \%$ acetic acid and $5 \mathrm{mM}$ ammonium acetate. The column temperature was $50^{\circ} \mathrm{C}$. ESI was in the negative mode, capillary voltage was $4 \mathrm{kV}$, and fragmentor voltage was $100 \mathrm{~V} . \mathrm{N}_{2}$ was used as drying gas at a flow rate of $13 \mathrm{~L} / \mathrm{min}$ and a temperature of $350{ }^{\circ} \mathrm{C}$. Nebulizer pressure was set at $60 \mathrm{psi}$. We monitored $[\mathrm{M}-\mathrm{H}]^{-}$in the selected-ion monitoring mode. Calibration curves were generated using commercial heptadecenoic acid (Nu-Chek Prep, $\mathrm{m} / \mathrm{z}=267)$.

Lipid extractions-Lipids were extracted using a chloroform/methanol mixture (2:1, v/v, $3 \mathrm{~mL}$ ) containing internal standards. The organic phases were collected, dried under $\mathrm{N}_{2}$ and dissolved in methanol/chloroform (3:1, v/v) for LC/MS analyses. 
LC/MS analysis-We used an Agilent 1100-LC system coupled to a 1946A-MS detector equipped with an ESI interface (Agilent Technologies, Inc., Palo Alto, CA). PEA was separated on an XDB Eclipse C18 column (50'4.6 mm i.d., $1.8 \mathrm{~mm}$, Zorbax, Agilent Technologies) with a gradient of methanol in water (from $85 \%$ to $90 \%$ methanol in $2.0 \mathrm{~min}$ and $90 \%$ to $100 \%$ in $3.0 \mathrm{~min}$ ) at a flow rate of $1.5 \mathrm{ml} / \mathrm{min}$. Column temperature was kept at $40{ }^{\circ} \mathrm{C}$. MS detection was in the positive ionization mode, capillary voltage was $3 \mathrm{kV}$ and fragmentor voltage was $120 \mathrm{~V}$. $\mathrm{N}_{2}$ was used as drying gas at a flow rate of $13 \mathrm{~L} / \mathrm{min}$ and a temperature of $350^{\circ} \mathrm{C}$. Nebulizer pressure was set at $60 \mathrm{psi}$.

Expression of recombinant NAAA-We amplified the full-length coding sequence of rat NAAA by polymerase chain reaction (PCR) using High Fidelity PCR Master (Roche, Indianapolis, IN) and rat brain cDNAs as templates. We designed two primers using sequences obtained from the NCBI database: 5'rNAAA (5'ATGGGGACCCCAGCCATCCGG-3') and 3'rNAAA (5'TCAGCTTGGGTTTCTGATCATGGT-3'). The PCR product was subcloned into a pCMVFlag vector (Stratagene, La Jolla, CA) by HindIII and XhoI (Roche, Indianapolis, IN) sites to construct a mammalian expression vector encoding Flag-tagged rNAAA. We transfected HEK293 cells with pCMV-Flag-rNAAA using SuperFect reagent (Qiagen, Valencia, CA) and screened with G418 $(0.3 \mathrm{mg} / \mathrm{mL})$. We harvested and washed cells stably expressing rNAAA, sonicated them in $20 \mathrm{mM}$ Tris- $\mathrm{HCl}$ (pH 7.5) with $0.32 \mathrm{M}$ sucrose, and centrifuged them at $800^{\prime} \mathrm{g}$ for $15 \mathrm{~min}$ at $4{ }^{\circ} \mathrm{C}$. The supernatant was ultra-centrifuged at $12,000^{\prime} \mathrm{g}$ for 30 min at $4{ }^{\circ} \mathrm{C}$. The pellet was suspended in phosphate-buffered saline (PBS) and subjected to 2 freeze-thaw cycles at $-80^{\circ} \mathrm{C}$. The suspension was centrifuged at $105,000^{\prime} \mathrm{g}$ for $1 \mathrm{~h}$ at $4{ }^{\circ} \mathrm{C}$, and the supernatant containing rNAAA was kept at $-80^{\circ} \mathrm{C}$ until use.

Carrageenan-induced inflammation-Sterile polyethylene sponges $\left(1 \mathrm{~cm}^{3}\right)$ were implanted under the dorsal skin of mice. Carrageenan (1.0\% in $90 \mu \mathrm{L}$ sterile saline/sponge), and drugs or vehicle (DMSO, $10 \mu \mathrm{L} /$ sponge) were instilled into the sponges, wounds were sutured and mice were allowed to recover. Seventy two hours following sponge implantation (2/mouse), mice were euthanized by cervical dislocation following isoflurane (Sigma) anesthesia and the sponges were collected. Volume of exudate and number of leukocytes were quantified using a hemocytometer.

\section{(c) Molecular modelling}

Molecular modelling studies were carried out employing a previously developed threedimensional model of rat NAAA-PEA tetrahedral adduct (residues 131-362),23 built using MODELLER 7.0 program,63 starting from the crystallographic coordinates of conjugated bile acid hydrolase (CBAH),20 a related member of the Ntn family. For the present work, in order to perform docking studies, PEA atoms were deleted from the active site, and the hydrogen atoms of the catalytic Cys131 were reassigned to form a hydrogen bond between the thiol hydrogen atom and its neutral nitrogen one. The resulting NAAA structure was submitted to a geometry optimization of hydrogen atoms, minimizing its energy to a gradient of $0.01 \mathrm{kcal} /(\mathrm{mol} \cdot \AA$ ) ) with the MMFF94s force field64 (as implemented in Macromodel).65 Inhibitor models were built using Maestro 8.566 and their geometries were optimised to an energy gradient of $0.01 \mathrm{kcal} /(\mathrm{mol} \cdot \AA)$ with the MMFF $94 \mathrm{~s}$ force field. Docking experiments were performed using Glide 5.067 starting from minimum-energy conformations of the ligands, placed in an arbitrary starting position within a region centered on residues Cys131, Asp150 and Asn292, using enclosing and bounding boxes of 20 and 10 $\AA$ on each side, respectively. Van der Waals radii of the protein atoms were not scaled, while Van der Waals radii of the ligand atoms, having partial atomic charges between -0.15 and 0.15 , were scaled by 0.8 . Standard precision mode was applied and docking solutions were ranked according to their $\mathrm{E}_{\text {model }}$ values. An alternative conformation of the NAAA 
model was generated by rearranging the side chains of Asn209 and Thr258 as shown in Figure $2 \mathrm{~B}$. The geometry of the resulting structure was optimized to an energy gradient of $0.01 \mathrm{kcal} /(\mathrm{mol} \cdot \hat{\mathrm{A}})$ and employed for docking, using the same computational settings as described above.

Docking complexes with compounds 7a and 8a, selected among the five poses having highest E-model scores, and having the lactone ring sufficiently close to Cys131 to allow a reactive event, were employed to build tetrahedral intermediates, by imposing a covalent bond between the $\beta$-lactone carbonyl carbon and the sulfur atom of Cys131. After model building of the covalent complexes, atom types and protonation states were opportunely modified and the resulting structures were minimized (with MMFF94s force field) to an energy-gradient of $0.05 \mathrm{kcal} /(\mathrm{mol} \cdot \AA$ Å), keeping the backbone atoms of the protein frozen.

\section{Acknowledgments}

This work was supported by Italian MiUR (Ministero dell'Università e della Ricerca), Universities of Parma and Urbino "Carlo Bo", the Sandler Foundation (to D.P.) and the National Institute on Drug Abuse (to D.P.).

\section{Abbreviations}

$\begin{array}{ll}\text { CBAH } & \text { conjugated bile acid hydrolase } \\ \text { LogP } \mathbf{P}_{\text {calc }} & \text { calculated } \log \mathrm{P} \\ \text { FAE } & \text { fatty acid ethanolamide } \\ \text { NAAA } & N \text {-acylethanolamine-hydrolyzing acid amidase } \\ \text { PEA } & \text { palmitoylethanolamide } \\ \text { PPAR } & \text { peroxisome proliferator-activated receptor } \\ \text { SAR } & \text { structure-activity relationship }\end{array}$

\section{References}

1. Russo R, LoVerme J, La Rana G, Compton TR, Parrott J, Duranti A, Tontini A, Mor M, Tarzia G, Calignano A, Piomelli D. The fatty acid amide hydrolase inhibitor URB597 (cyclohexylcarbamic acid 3'-carbamoylbiphenyl-3-yl ester) reduces neuropathic pain after oral administration in mice. J Pharmacol Exp Ther. 2007; 322:236-242. [PubMed: 17412883]

2. McKinney MK, Cravatt BF. Structure and function of fatty acid amide hydrolase. Annu Rev Biochem. 2005; 74:411-432. [PubMed: 15952893]

3. Di Marzo V. Targeting the endocannabinoid system: to enhance or reduce? Nat Rev Drug Discov. 2008; 7:438-455. [PubMed: 18446159]

4. Mazzari S, Canella R, Petrelli L, Marcolongo G, Leon A. N-(2-Hydroxyethyl)hexadecanamide is orally active in reducing edema formation and inflammatory hyperalgesia by down-modulating mast cell activation. Eur J Pharmacol. 1996; 300:227-236. [PubMed: 8739213]

5. Calignano A, La Rana G, Giuffrida A, Piomelli D. Control of pain initiation by endogenous cannabinoids. Nature. 1998; 394:277-281. [PubMed: 9685157]

6. Lo Verme J, Fu J, Astarita G, La Rana G, Russo R, Calignano A, Piomelli D. The nuclear receptor peroxisome proliferator-activated receptor- $\alpha$ mediates the anti-inflammatory actions of palmitoylethanolamide. Mol Pharmacol. 2005; 67:15-19. [PubMed: 15465922]

7. LoVerme J, Russo R, La Rana G, Fu J, Farthing J, Mattace-Raso G, Meli R, Hohmann A, Calignano A, Piomelli D. Rapid broad-spectrum analgesia through activation of peroxisome proliferatoractivated receptor- $\alpha$. J Pharmacol Exp Ther. 2006; 319:1051-1061. [PubMed: 16997973]

8. Petrosino S, Iuvone T, Di Marzo V. N-palmitoyl-ethanolamine: biochemistry and new therapeutic opportunities. Biochimie. 2010; 92:724-727. [PubMed: 20096327] 
9. Costa B, Comelli F, Bettoni I, Colleoni M, Giagnoni G. The endogenous fatty acid amide, palmitoylethanolamide, has anti-allodynic and anti-hyperalgesic effects in a murine model of neuropathic pain: involvement of $\mathrm{CB}_{1}$, TRPV1 and PPAR $\gamma$ receptors and neurotrophic factors. Pain. 2008; 139:541-550. [PubMed: 18602217]

10. Bisogno T, Maurelli S, Melck D, De Petrocellis L, Di Marzo V. Biosynthesis, uptake, and degradation of anandamide and palmitoylethanolamide in leukocytes. J Biol Chem. 1997; 272:3315-3323. [PubMed: 9013571]

11. Liu J, Wang L, Harvey-White J, Osei-Hyiaman D, Razdan R, Gong Q, Chan AC, Zhou Z, Huang BX, Kim H-Y, Kunos G. A biosynthetic pathway for anandamide. Proc Natl Acad Sci USA. 2006; 103:13345-13350. [PubMed: 16938887]

12. Ueda N, Yamanaka K, Yamamoto S. Purification and characterization of an acid amidase selective for $N$-palmitoylethanolamine, a putative endogenous anti-inflammatory substance. J Biol Chem. 2001; 276:35552-35557. [PubMed: 11463796]

13. Tsuboi K, Sun YX, Okamoto Y, Araki N, Tonai T, Ueda N. Molecular characterization of $N$ acylethanolamine-hydrolyzing acid amidase, a novel member of the choloylglycine hydrolase family with structural and functional similarity to acid ceramidase. J Biol Chem. 2005; 280:11082-11092. [PubMed: 15655246]

14. Tsuboi K, Takezaki N, Ueda N. The $N$-acylethanolamine-hydrolyzing acid amidase (NAAA). Chem Biodivers. 2007; 4:1914-1925. [PubMed: 17712833]

15. Mor M, Rivara S, Lodola A, Plazzi PV, Tarzia G, Duranti A, Tontini A, Piersanti G, Kathuria S, Piomelli D. Cyclohexylcarbamic acid 3'- or 4'-substituted biphenyl-3-yl esters as fatty acid amide hydrolase inhibitors: synthesis, quantitative structure-activity relationships, and molecular modeling studies. J Med Chem. 2004; 47:4998-5008. [PubMed: 15456244]

16. Kathuria S, Gaetani S, Fegley D, Valiño F, Duranti A, Tontini A, Mor M, Tarzia G, La Rana G, Calignano A, Giustino A, Tattoli M, Palmery M, Cuomo V, Piomelli D. Modulation of anxiety through blockade of anandamide hydrolysis. Nat Med. 2003; 9:76-81. [PubMed: 12461523]

17. Tsuboi K, Hilligsmann C, Vandevoorde S, Lambert DM, Ueda N. Ncyclohexanecarbonylpentadecylamine: A selective inhibitor of the acid amidase hydrolysing $\mathrm{N}$ acylethanolamines, as a tool to distinguish acid amidase from fatty acid amide hydrolase. Biochem J. 2004; 379:99-106. [PubMed: 14686878]

18. Vandevoorde S, Tsuboi K, Ueda N, Jonsson K-O, Fowler CJ, Lambert DM. Esters, retroesters, and a retroamide of palmitic acid: pool for the first selective inhibitors of $N$-palmitoylethanolamineselective acid amidase. J Med Chem. 2003; 46:4373-4376. [PubMed: 14521402]

19. Saturnino C, Petrosino S, Ligresti A, Palladino C, De Martino G, Bisogno T, Di Marzo V. Synthesis and biological evaluation of new potential inhibitors of $\mathrm{N}$-acylethanolamine hydrolyzing acid amidase. Bioorg Med Chem Lett. 2010; 20:1210-1213. [PubMed: 20022504]

20. Rossocha M, Schultz-Heienbrok R, von Moeller H, Coleman JP, Saenger W. Conjugated bile acid hydrolase is a tetrameric $\mathrm{N}$-terminal thiol hydrolase with specific recognition of its cholyl but not of its tauryl product. Biochemistry. 2005; 44:5739-5748. [PubMed: 15823032]

21. Zhao L-Y, Tsuboi K, Okamoto Y, Nagahata S, Ueda N. Proteolytic activation and glycosylation of $\mathrm{N}$-acylethanolamine-hydrolyzing acid amidase, a lysosomal enzyme involved in the endocannabinoid metabolism. Biochim Biophys Acta. 2007; 1771:1397-1405. [PubMed: 17980170]

22. Wang J, Zhao L-Y, Uyama T, Tsuboi K, Tonai T, Ueda N. Amino acid residues crucial in pH regulation and proteolytic activation of $N$-acylethanolamine-hydrolyzing acid amidase. Biochim Biophys Acta. 2008; 1781:710-717. [PubMed: 18793752]

23. Solorzano C, Zhu C, Battista N, Astarita G, Lodola A, Rivara S, Mor M, Russo R, Maccarrone M, Antonietti F, Duranti A, Tontini A, Cuzzocrea S, Tarzia G, Piomelli D. Selective $N$ acylethanolamine-hydrolyzing acid amidase inhibition reveals a key role for endogenous palmitoylethanolamide in inflammation. Proc Natl Acad Sci US A. 2009; 106:20966-20971.

24. Mayer RJ, Louis-Flamberg P, Elliott JD, Fisher M, Leber J. Inhibition of 3-hydroxy-3methylglutaryl coenzyme A synthase by antibiotic 1233A and other $\beta$-lactones. Biochem Biophys Res Commun. 1990; 169:610-616. [PubMed: 1972621] 
25. Chauhan D, Hideshima T, Anderson KC. A novel proteasome inhibitor NPI-0052 as an anticancer therapy. Br J Cancer. 2006; 95:961-965. [PubMed: 17047643]

26. Lall MS, Ramtohul YK, James MNG, Vederas JC. Serine and threonine $\beta$-lactones: A new class of hepatitis A virus 3C cysteine proteinase inhibitors. J Org Chem. 2002; 67:1536-1547. [PubMed: 11871884]

27. Arnold LD, Kalantar TH, Vederas JC. Conversion of serine to stereochemically pure $\beta$-substituted $\alpha$-amino acids via $\beta$-lactones. J Am Chem Soc. 1985; 107:7105-7109.

28. Arnold LD, May RG, Vederas JC. Synthesis of optically pure $\alpha$-amino acids via salts of $\alpha$-amino$\beta$-propiolactone. J Am Chem Soc. 1988; 110:2237-2241.

29. Marinez ER, Salmassian EK, Lau TT, Gutierrez CG. Enterobactin and enantioenterobactin. J Org Chem. 1996; 61:3548-3550.

30. Sliedregt KM, Schouten A, Kroon J, Liskamp RMJ. Reaction of N-trityl amino acids with BOP: Efficient synthesis of $t$-butyl esters as well as $\mathrm{N}$-trytil serine- and threonine- $\beta$-lactones. Tetrahedron Lett. 1996; 37:4237-4240.

31. Parker WL, Rathnum ML, Liu WC. SQ 26,517 - A $\beta$-lactone produced by a Bacillus species. J Antibiot. 1982; 35:900-902. [PubMed: 7174539]

32. Montalbetti CAGN, Falque V. Amide bond formation and peptide coupling. Tetrahedron. 2005; 61:10827-10852.

33. White AJ, Wharton CW. Hydrogen-bonding in enzyme catalysis. Fourier-trasform infrared detection of ground-state electronic strain in acyl-chymotrypsins and analysis of the kinetic consequences. Biochem J. 1990; 270:627-637. [PubMed: 2241898]

34. Geske GD, O’Neill JC, Miller DM, Mattmann ME, Blackwell HE. Modulation of bacterial quorum sensing with synthetic ligands: Systematic evaluation of $N$-acylated homoserine lactones in multiple species and new insights into their mechanism of action. J Am Chem Soc. 2007; 129:13613-13625. [PubMed: 17927181]

35. Hutchinson A. Note on the reduction of aromatic amides. J Chem Soc Trans. 1890; 57:957.

36. Bessodes M, Saiah M, Antonakis K. A new, versatile and stereospecific route to unusual amino acids: the enantiospecific total synthesis of statine amide and its three stereoisomers. J Org Chem. 1992; 57:4441-4444.

37. Hofmann K, Schmiechen R, Wells RD, Wolman Y, Yanaihara N. Studies on Polypeptides. XXIX. Synthetic peptides related to the N-terminus of bovine pancreatic ribonuclease A (Position 1-7). J Am Chem Soc. 1965; 87:611-619. [PubMed: 14263386]

38. Miller MJ, Mattingly PG, Morrison MA, Kerwin JF Jr. Synthesis of $\beta$-lactams from substituted hydroxamic acids. J Am Chem Soc. 1980; 102:7026-7032.

39. Cohen SB, Halcomb RL. Application of serine- and threonine-derived cyclic sulfamidates for the preparation of $S$-linked glycosyl amino acids in solution- and solid-phase peptide synthesis. J Am Chem Soc. 2002; 124:2534-2543. [PubMed: 11890803]

40. Higashibayashi S, Kohno M, Goto T, Suzuki K, Mori T, Hashimoto K, Nakata M. Synthetic studies on thiostrepton family of peptide antibiotics: synthesis of the pentapeptide segment containing dihydroxyisoleucine, thiazoline and dehydroamino acid. Tetrahedron Lett. 2004; 45:3707-3712.

41. Pu Y, Martin FM, Vederas JC. Synthesis and acylation of salts of L-threonine $\beta$-lactone: A route to $\beta$-lactone antibiotics. J Org Chem. 1991; 56:1280-1283.

42. Sakai N, Ageishi S, Isobe H, Hayashi Y, Yamamoto Y. Lipase promoted asymmetric transesterification of 4-alkyl-, 3-alkyl- and 3,4-dialkyloxetan-2-ones with ring-opening. J Chem Soc, Perkin Trans. 2000; 1:71-77.

43. Park DJ, Kim DH. Cysteine derivatives as inhibitors for carboxypeptidase A: Synthesis and structure-activity relationships. J Med Chem. 2002; 45:911-918. [PubMed: 11831903]

44. Gomberg M, Pernert JC. Methylbiphenyls. J Am Chem Soc. 1926; 48:1372-1384.

45. Xiao Z-Y, Zhao X, Jiang X-K, Li Z-T. Self-assembly of porphyrin-azulene-porpfyrin and porphyrin-azulene-conjugates. Org Biomol Chem. 2009; 7:2540-2547. [PubMed: 19503927]

46. Fraser RTM, Taube H. Activation effects and rates of electron transfer. J Am Chem Soc. 1961; 83:2242-2246. 
47. Deng Y, Gong L, Mi A, Liu H, Jiang Y. Suzuki coupling catalyzed by ligand-free palladium(II) species at room temperature and by exposure to air. Synthesis. 2003:337-339.

48. Müller CE, Schobert U, Hipp J, Geis U, Frobenius W, Pawlowski M. Configurationally stable analogs of styrylxanthines as $\mathrm{A}_{2 \mathrm{~A}}$ adenosine receptor antagonists. Eur J Med Chem. 1997; 32:709-719.

49. Orton KJP, Soper FG, Wiliams G. The chlorination of anilides. Part III. $N$-Chlorination and $C$ chlorination as simultaneous side reactions. J Chem Soc. 1928:998-1005.

50. Cativiela C, Serrano JL, Zurbano MM. Synthesis of 3-substituted pentane-2,4-diones: Valuable intermediates for liquid crystals. J Org Chem. 1995; 60:3074-3083.

51. Yin J, Bergmann EM, Cherney MM, Lall MS, Jain RP, Vederas JC, James MNG. Dual modes of modification of hepatitis A virus $3 \mathrm{C}$ protease by a serine-derived $\beta$-lactone: Selective crystallization and formation of a functional catalytic triad in the active site. J Mol Biol. 2005; 354:854-871. [PubMed: 16288920]

52. Tomoda H, Ohbayashi N, Morikawa Y, Kumagai H, Omura S. Binding site for fungal $\beta$-lactone hymeglusin on cytosolic 3-hydroxy-3-methylglutaryl coenzyme A synthase. Biochim Biophys Acta. 2004; 1636:22-28. [PubMed: 14984735]

53. Greenspan MD, Bull HG, Yudkovitz JB, Hanf DP, Alberts AW. Inhibition of 3-hydroxy-3methylglutaryl-CoA synthase and cholesterol biosynthesis by $\beta$-lactone inhibitors and binding of these inhibitors to the enzyme. Biochem J. 1993; 289:889-895. [PubMed: 8094614]

54. Pojer F, Ferrer JL, Richard SB, Nagegowda DA, Chye M-L, Bach TJ, Noel JP. Structural basis for the design of potent and species-specific inhibitors of 3-hydroxy-3-methylglutaryl CoA synthases. Proc Natl Acad Sci USA. 2006; 103:11491-11496. [PubMed: 16864776]

55. ACD/LogP, version 800. Advanced Chemistry Development, Inc; Toronto ON, Canada: 2004. www.acdlabs.com

56. Oliver CM, Schaefer AM, Greenberg EP, Sufrin JR. Microvawe synthesis and evaluation of phenacylhomoserine lactones as anticancer compounds that minimally activate quorum sensing pathways in Pseudomonas aeruginosa. J Med Chem. 2009; 52:1569-1575. [PubMed: 19260689]

57. Lu X, Lin S. Pd(II)-Bipyridine catalyzed conjugate addition of arylboronic acid to $\alpha, \beta$-unsaturated carbonyl compounds. J Org Chem. 2005; 70:9651-9653. [PubMed: 16268654]

58. Wang Z, Gu C, Colby T, Shindo T, Balamurugan R, Waldmann H, Kaiser M, van der Hoorn RAL. $\beta$-Lactone probes identify a papain-like peptide ligase in Arabidopsis thaliana. Nat Chem Biol. 2008; 4:557-563. [PubMed: 18660805]

59. Tao B, Boykin DW. Simple amine/Pd(OAc) $)_{2}$-catalyzed Suzuki coupling reactions of aryl bromides under mild aerobic conditions. J Org Chem. 2004; 69:4330-4335. [PubMed: 15202886]

60. Tzschucke CC, Bannwart W. Fluorous-silica-supported perfluoro-tagged palladium complexes catalyze Suzuki couplings in water. Helv Chim Acta. 2004; 87:2882-2889.

61. Chase BH. Ester exchange in the hydrolysis of diphenyl terephthalate. J Chem Soc. 1963:13341335.

62. Wietzerbin K, Bernadou J, Meunier B. Mechanism of the catalytic oxidation of tertiary alcohols by the water-soluble $\mathrm{Mn}-\mathrm{TMPyP} / \mathrm{KHSO}_{5}$ system: $\beta$-Fragmentation versus $O$-neophyl rearrangement. Eur J Inorg Chem. 1999; 9:1467-1477.

63. Sali A, Blundell TL. Comparative protein modelling by satisfaction of spatial restraints. J Mol Biol. 1993; 234:779-815. [PubMed: 8254673]

64. Halgren TA. MMFF VI. MMFF94s option for energy minimization studies. J Comput Chem. 1999; 20:720-729.

65. Macromodel version 85. Schrödinger L.L.C; New York, NY: 2008.

66. Maestro, version 85. Schrödinger, L.L.C; New York, NY: 2008.

67. Friesner RA, Banks JL, Murphy RB, Halgren TA, Klicic JJ, Mainz DT, Repasky MP, Knoll EH, Shelley M, Perry JK, Shaw DE, Francis P, Shenkin PS. Glide: A new approach for rapid, accurate docking and scoring. 1. Method and assessment of docking accuracy. J Med Chem. 2004; 47:1739-1749. [PubMed: 15027865] 


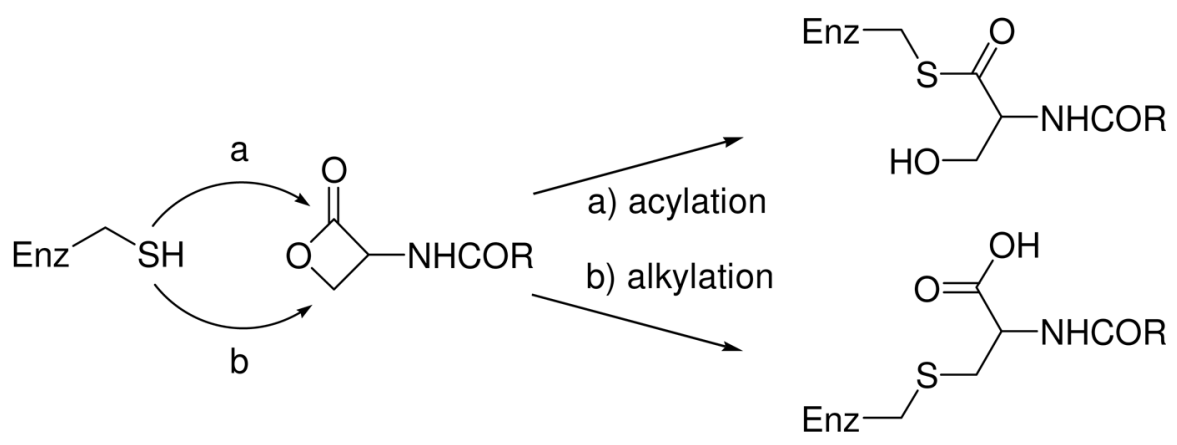

Figure 1.

Possible mechanisms for covalent inactivation of NAAA by lactone derivatives. 


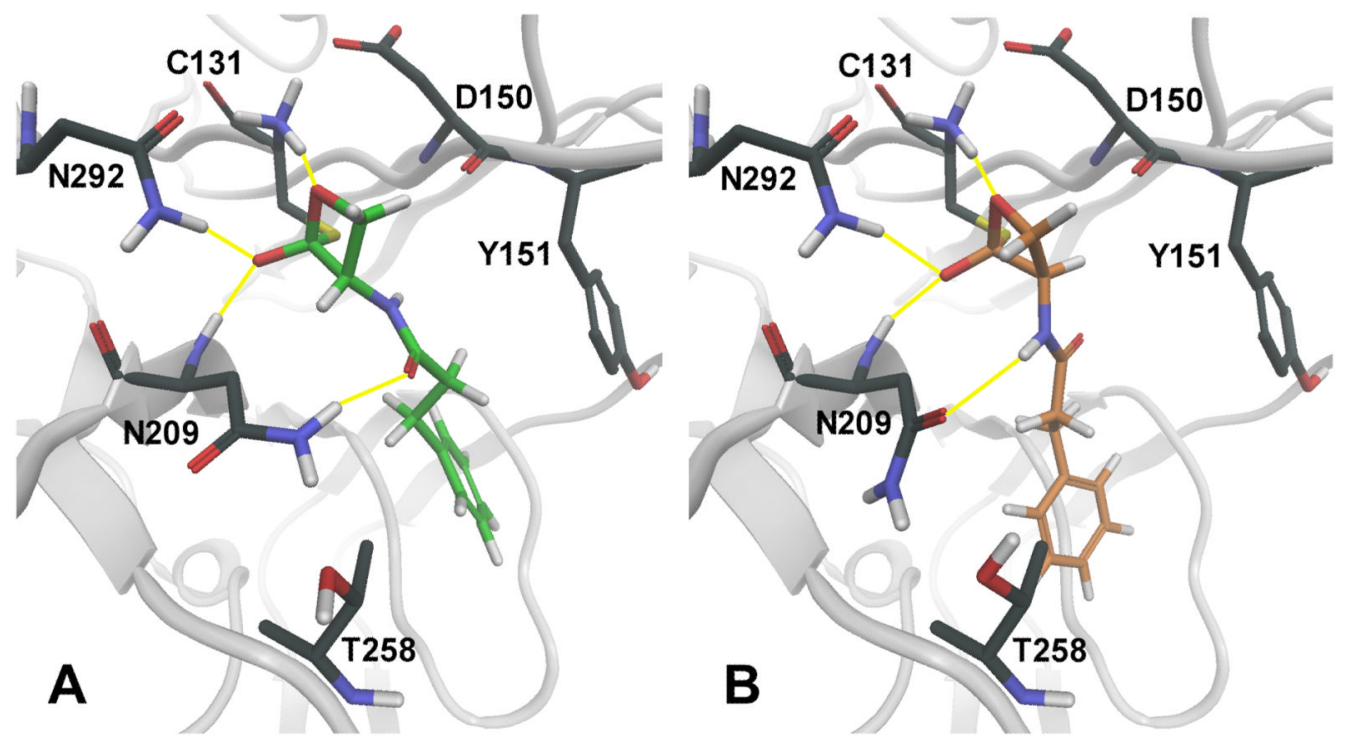

Figure 2.

Representation of the putative tetrahedral intermediates resulting from the nucleophilic attack of catalytic cysteine 131 onto the lactone carbonyl of 7a (A, green carbons) or $\mathbf{8 a}$ (B, orange carbons). The backbone of the NAAA model, built by comparative modeling, is represented in grey. Hydrogen bonds between enzyme residues and the inhibitor are symbolized by yellow lines. Standard-atom color codes: black: carbon; red: oxygen; blue: nitrogen; white: hydrogen; yellow: sulfur. 


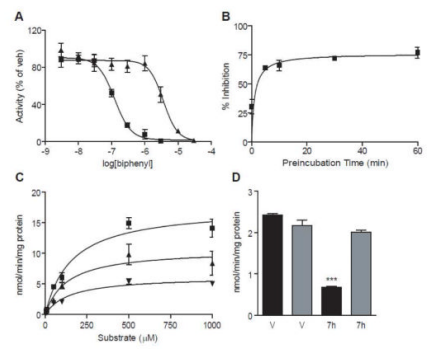

Figure 3.

Characterization of NAAA inhibition by compound $\mathbf{7 h}$ in vitro. (A) Concentration-response curves for inhibition of NAAA by $\mathbf{7 g}$ (meta-biphenyl derivative, closed triangles) and $\mathbf{7 h}$ (para-biphenyl derivative, closed squares). (B) Preincubation time-course of $\mathbf{7 h}$. (C) Michaelis-Menten analysis of $\mathbf{7 h}$ (vehicle - closed squares; $100 \mathrm{nM} \mathbf{7 h}$ : closed upright triangles; $200 \mathrm{nM} \mathbf{7 h}$ : closed inverted triangles). (D) Overnight dialysis of $\mathbf{7 h}$ (pre-dialysis: filled bars; post-dialysis: shaded bars). $* * * \mathrm{P}<0.001$ vs vehicle-preincubation $(\mathrm{n}=3-5)$. 
A

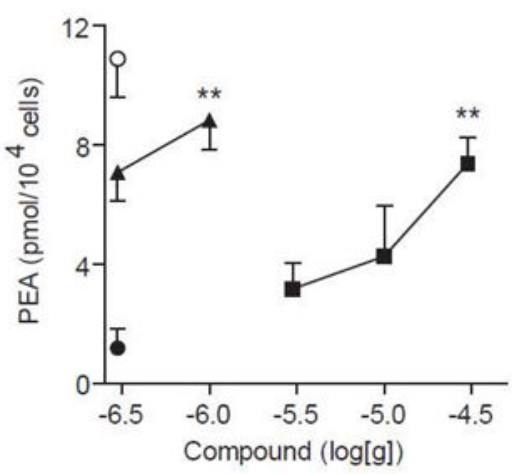

B

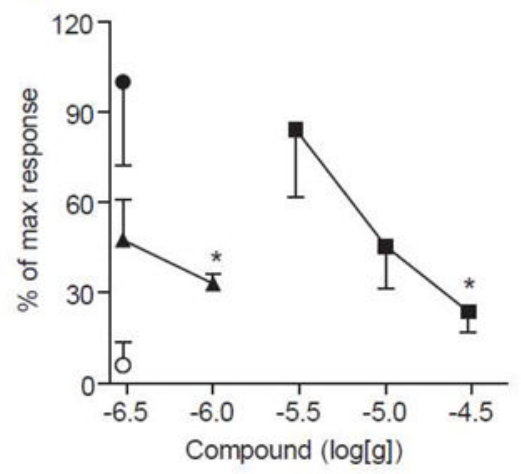

Figure 4.

(A) Effects of compounds 7a and $\mathbf{7 h}$ on PEA levels in infiltrating leukocytes collected from carrageenan-instilled sponges implanted beneath the mouse skin. (B) Effects of compounds 7a and $7 \mathbf{h}$ on number of infiltrating leukocytes elicited by carrageenan. Open circles: vehicle/vehicle; closed circles: carrageenan/vehicle; closed triangles: carrageenan/7h; closed squares: carrageenan/7a. $* * \mathrm{P}<0.01$ vs carrageenan/vehicle; $* \mathrm{P}<0.05$ vs carrageenan/ vehicle; $(\mathrm{n}=3-5)$. 


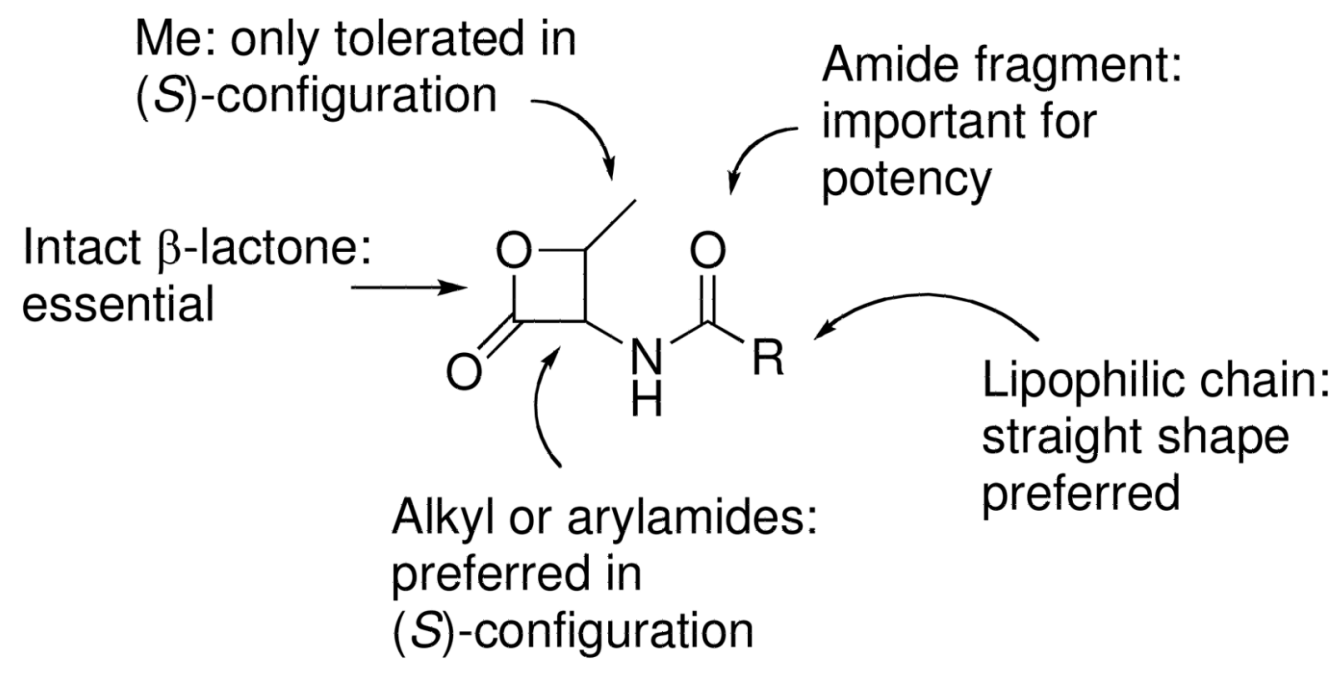

Figure 5.

Summary of SARs for $\beta$-lactone inhibitors of NAAA. 

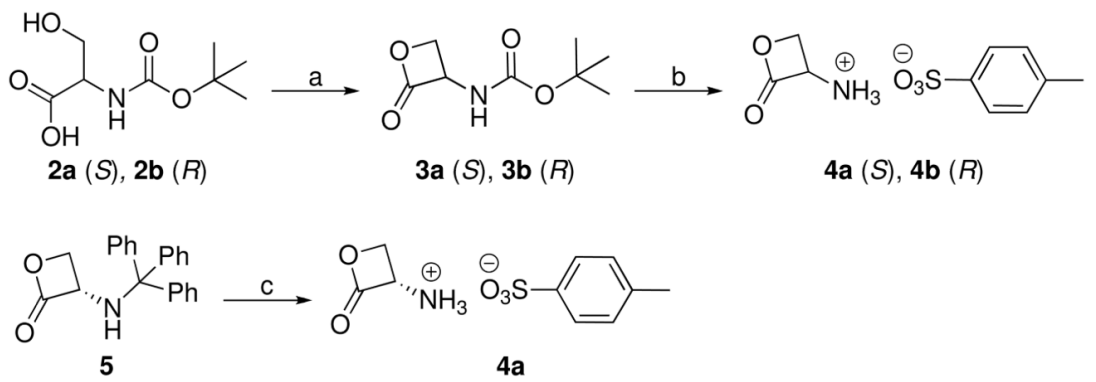

Scheme 1.

${ }^{a}$ Reagents and conditions: (a) $\mathrm{PPh}_{3}$, DMAD, THF, $-78{ }^{\circ} \mathrm{C}, 20 \mathrm{~min}$, then room temperature, $2.5 \mathrm{~h}$; (b) $\mathrm{CF}_{3} \mathrm{COOH}, p$-TsOH, $0{ }^{\circ} \mathrm{C}, 10-15 \mathrm{~min}$; (c) $\mathrm{CH}_{2} \mathrm{Cl}_{2} / \mathrm{CF}_{3} \mathrm{COOH}, p-\mathrm{TsOH}, 0{ }^{\circ} \mathrm{C}, 0.5$ h. 


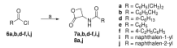

Scheme 2.

${ }^{a}$ Reagents and conditions: (a) $\mathbf{4 a}$ or $\mathbf{4 b}, \mathrm{Et}_{3} \mathrm{~N}, \mathrm{CH}_{2} \mathrm{Cl}_{2}, 0{ }^{\circ} \mathrm{C}, 0.5 \mathrm{~h}$ then room temperature, 2 h. 
<smiles>[R]C(=O)O</smiles>

9c,g,h,k-n<smiles>C[13CH3]</smiles>

c $\mathrm{R}=\mathrm{C}_{6} \mathrm{H}_{5}\left(\mathrm{CH}_{2}\right)_{6}$

g $\mathrm{R}=$ biphenyl-3-yl

h $\mathrm{R}=$ biphenyl-4-yl

k $R=6$-ethoxycarbonylnaphthalen-2-yl

I $R=6$-methoxynaphthalen-2-yl

$\mathrm{m} R=4$-phenoxycarbonylphenyl

n $R=4$-benzyloxyphenyl

Scheme 3.

${ }^{a}$ Reagents and conditions: (a) $(\mathrm{COCl})_{2}$, DMF, $\mathrm{CH}_{2} \mathrm{Cl}_{2}, 0{ }^{\circ} \mathrm{C}, 0.5 \mathrm{~h}$ then room temperature, 3-16 h; (b) 4a, $\mathrm{Et}_{3} \mathrm{~N}, \mathrm{CH}_{2} \mathrm{Cl}_{2}$ (or THF), $0{ }^{\circ} \mathrm{C}, 0.5 \mathrm{~h}$ then room temperature, $3 \mathrm{~h}$. 


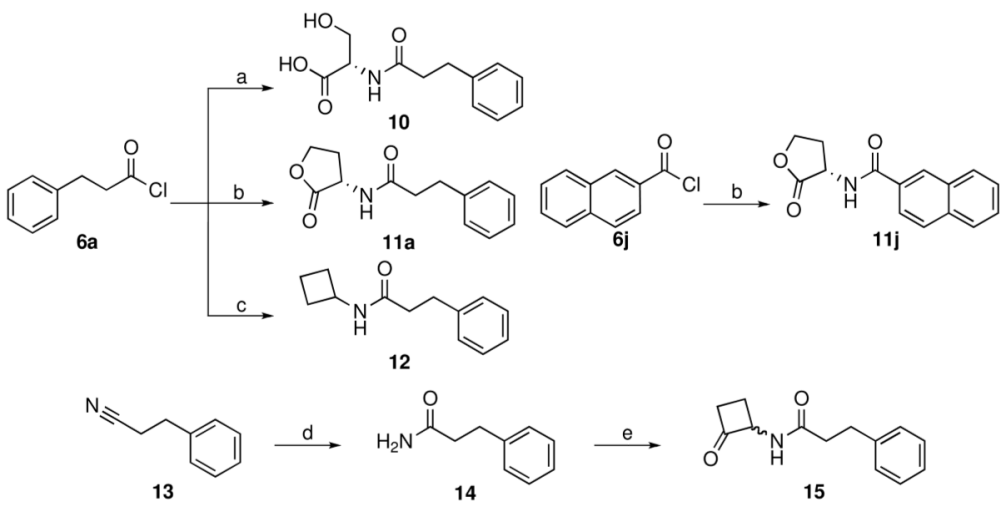

Scheme 4.

${ }^{a}$ Reagents and conditions: (a) L-serine, $\mathrm{NaOH}, 0{ }^{\circ} \mathrm{C}, 4 \mathrm{~h}$; (b,c) $(S)$-3-aminodihydrofuran-2one. $\mathrm{HBr}$ or $\mathrm{c}-\mathrm{C}_{4} \mathrm{H}_{7} \mathrm{NH}_{2}, \mathrm{Et}_{3} \mathrm{~N}, \mathrm{CH}_{2} \mathrm{Cl}_{2}, 0^{\circ} \mathrm{C}$-room temperature, 3-3.5 h; (d) $t$ - $\mathrm{BuOH} / \mathrm{H}_{2} \mathrm{O}$, $\mathrm{NaOH}, \mathrm{H}_{2} \mathrm{O}_{2}$, room temperature, $3 \mathrm{~h}$; (e) 1,2-bis(trimethylsilanyloxy)cyclobutene, THF, $\mathrm{HCl} / \mathrm{Et}_{2} \mathrm{O}$, reflux, $3 \mathrm{~h}$. 
<smiles>C[14CH2][14CH2][14CH2]C(N)C(C)O</smiles>

16a $(2 S, 3 R)$

$16 \mathrm{~b}(2 R, 3 S)$<smiles>CC(O)C(NC(=O)OC(C)(C)C)C(=O)O</smiles>

17a $(2 S, 3 R)$

$17 \mathrm{~b}(2 R, 3 S)$<smiles>C=C</smiles><smiles>CC1OC(=O)C1NC(=O)OC(C)(C)C</smiles>

18a $(2 R, 3 S)$ $18 \mathrm{~b}(2 S, 3 R)$
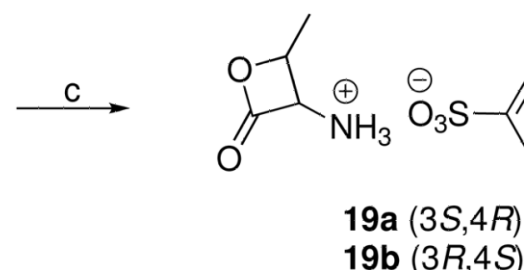<smiles>CC1CC1</smiles><smiles>CC1OC(=O)C1NC(=O)CCc1ccccc1</smiles>

20a $(2 R, 3 S)$

$20 \mathrm{~b}(2 S, 3 R)$

Scheme 5.

${ }^{a}$ Reagents and conditions: (a) $\mathrm{Boc}_{2} \mathrm{O}, \mathrm{NaHCO}_{3}, \mathrm{H}_{2} \mathrm{O}, \mathrm{MeOH}$, room temperature, $36 \mathrm{~h}$; (b) BOP, $\mathrm{Et}_{3} \mathrm{~N}, \mathrm{CH}_{2} \mathrm{Cl}_{2}$, room temperature, $3 \mathrm{~h}$; (c) $\mathrm{CF}_{3} \mathrm{COOH}, p-\mathrm{TsOH}, 0{ }^{\circ} \mathrm{C}, 0.25 \mathrm{~h}$; (d) 6a, $\mathrm{Et}_{3} \mathrm{~N}, \mathrm{CH}_{2} \mathrm{Cl}_{2}, 0{ }^{\circ} \mathrm{C}, 0.5 \mathrm{~h}$ then room temperature, $3 \mathrm{~h}$. 


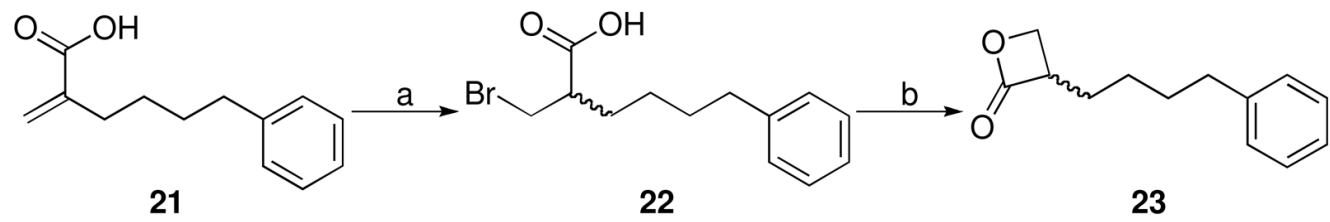

Scheme 6.

${ }^{a}$ Reagents and conditions: (a) $\mathrm{HBr} / \mathrm{AcOH}, \mathrm{CH}_{2} \mathrm{Cl}_{2}, 0{ }^{\circ} \mathrm{C}, 3 \mathrm{~h}$ then room temperature, $52 \mathrm{~h}$; (b) $\mathrm{NaOH}, \mathrm{CHCl}_{3}$, room temperature, $2 \mathrm{~h}$. 
<smiles>O=Cc1cccc(Br)c1</smiles>

24<smiles>O=C(O)c1ccc2cc(C(=O)O)ccc2c1</smiles>

26<smiles>O=C(Cl)c1ccc(C(=O)Cl)cc1</smiles>

27<smiles>O=C(O)c1ccc(O)cc1</smiles>

28<smiles>C=CC</smiles><smiles>OCc1ccccc1</smiles>

25<smiles>CCC</smiles>

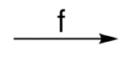

a, b<smiles>O=C(O)c1cccc(-c2ccccc2)c1</smiles>

$9 g$<smiles>CCOC(=O)c1ccc2cc(C(=O)O)ccc2c1</smiles>

9k<smiles>O=C(O)c1ccc(C(=O)Oc2ccccc2)cc1</smiles>

$9 \mathrm{~m}$<smiles>O=C(O)c1ccc(OCc2ccccc2)cc1</smiles>

9n

Scheme 7.

${ }^{a}$ Reagents and conditions: (a) $\mathrm{Bu}_{4} \mathrm{NBr}, \mathrm{K}_{2} \mathrm{CO}_{3}, \mathrm{PdCl}_{2}$, EtOH, room temperature, $3 \mathrm{~h}$; (b) $\mathrm{KMnO}_{4}, \mathrm{CH}_{3} \mathrm{C}(\mathrm{O}) \mathrm{CH}_{3}, \mathrm{H}_{2} \mathrm{O}$, room temperature, $5 \mathrm{~h}$; (c) EtBr, Et ${ }_{3} \mathrm{~N}, \mathrm{DMF}, 80^{\circ} \mathrm{C}, 4 \mathrm{~h}$; (d) $\mathrm{PhOH}, \mathrm{Et}_{3} \mathrm{~N}, \mathrm{MeCN}$, room temperature, 4 h; (e) $\mathrm{Na}_{2} \mathrm{CO}_{3}$, room temperature, $15 \mathrm{~h}$; (f) $\mathrm{BnBr}$, $\mathrm{KOH}, \mathrm{EtOH} / \mathrm{H}_{2} \mathrm{O}$, reflux, $24 \mathrm{~h}$. 


\section{Table 1}

Inhibitory Potencies $\left(\mathrm{IC}_{50}\right)$ of Tested Compounds $\mathbf{1 , 7 a - d , 8 a , 1 0 , 1 1 a , 1 2 , 1 5 , 2 0 a , b 2 3 , ~ o n ~ r a t ~ N A A A ~ A c t i v i t y . ~}$

\begin{tabular}{ccc}
\hline Cpds. & Structure & IC $_{50}(\mathbf{n M}) \pm$ S.E.M. \\
\hline 1 & $2,960 \pm 30023$
\end{tabular}

$7 a$<smiles>O=C(CCc1ccccc1)NC1COC1=O</smiles>

$420 \pm 2023$

8a<smiles>O=C(CCc1ccccc1)N[C@H]1COC1=O</smiles>

$6,000 \pm 60023$

10

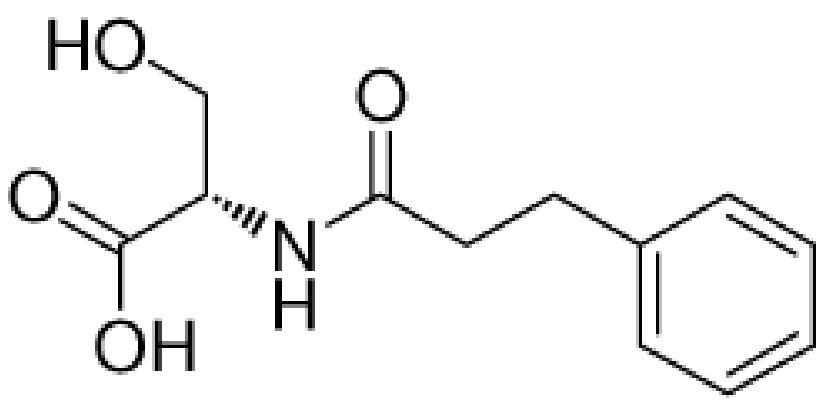

11a<smiles>O=C(CCc1ccccc1)N[C@H]1CCOC1=O</smiles>

12<smiles>O=C(CCc1ccccc1)NC1CCC1</smiles>

$>100,000$

15

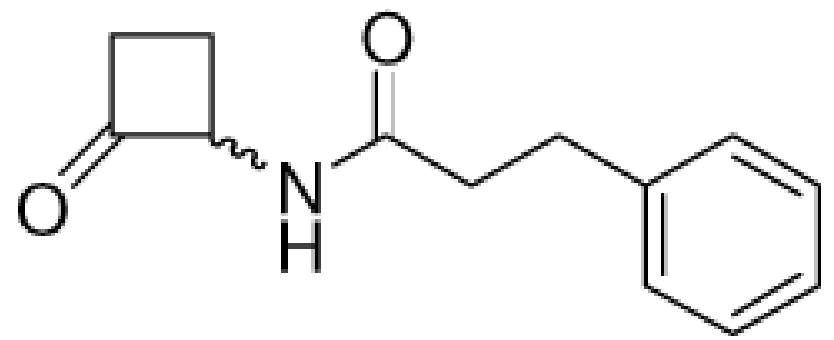

$>100,000$

$>100,00023$

$>100,00023$

20a<smiles>CC1OC(=O)C1NC(=O)CCc1ccccc1</smiles>

$>100,000$ 


\begin{tabular}{llc}
\hline Cpds. & Structure & IC $_{50}(\mathbf{n M}) \pm$ S.E.M. \\
\hline $20 \mathrm{~b}$ & $3,200 \pm 400$
\end{tabular}

23

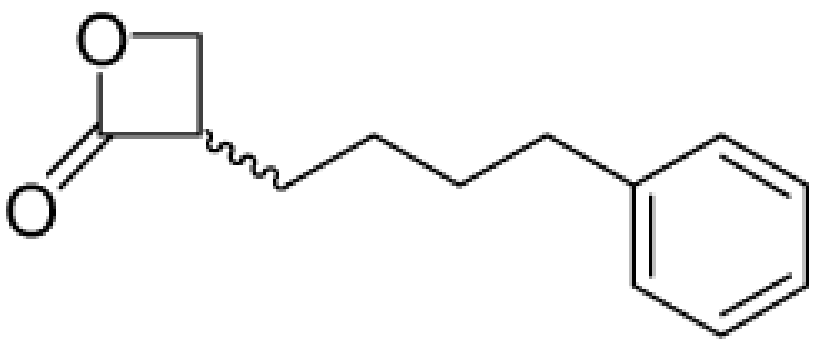

$7 b$

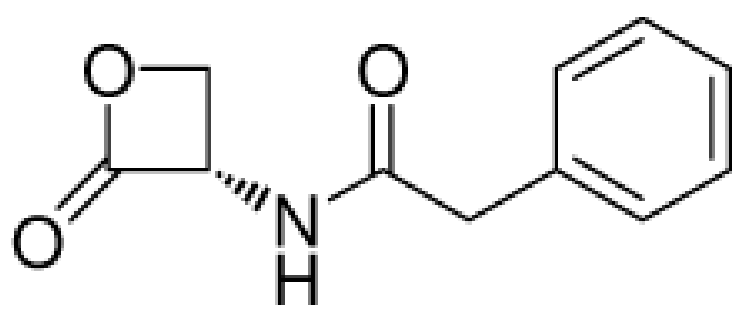

$11,000 \pm 2,200$

$7 \mathrm{c}$<smiles>O=C(CCCCCCc1ccccc1)N[C@H]1COC1=O</smiles>

$1,850 \pm 200$

$1,500 \pm 100$

$460 \pm 100$

7d<smiles>CCCCCCC(=O)NC1COC1=O</smiles> 
Table 2

Inhibitory Potencies $\left(\mathrm{IC}_{50}\right)$ of $N$-(2-Oxo-3-oxetanyl)arylamides $(\mathbf{7 e - 7 n}, \mathbf{8 j}, \mathbf{1 1} \mathbf{j})$ on Rat NAAA Activity.

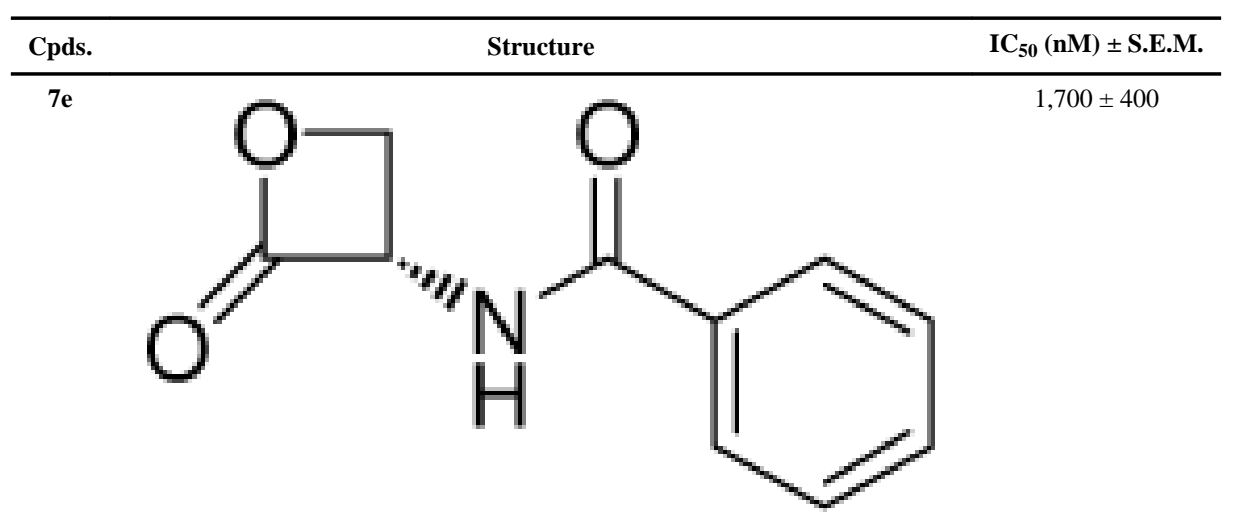

$7 \mathbf{f}$

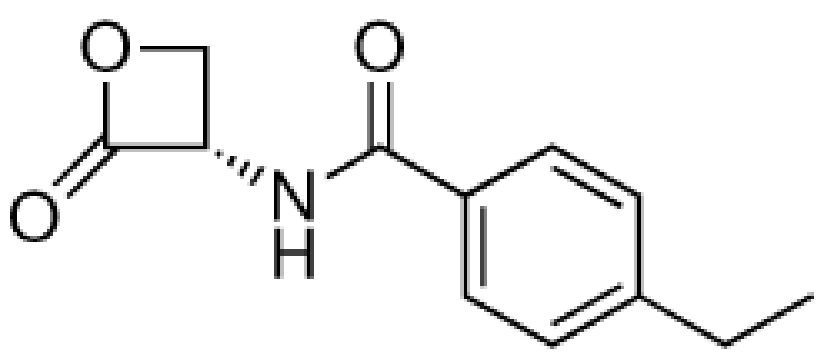

$7 \mathbf{i}$<smiles>O=C(N[C@@H]1COC1=O)c1cccc2ccccc12</smiles>

$7 \mathbf{j}$<smiles>O=C(NC1NCC1=O)c1ccc2ccccc2c1</smiles>

$8 \mathbf{j}$

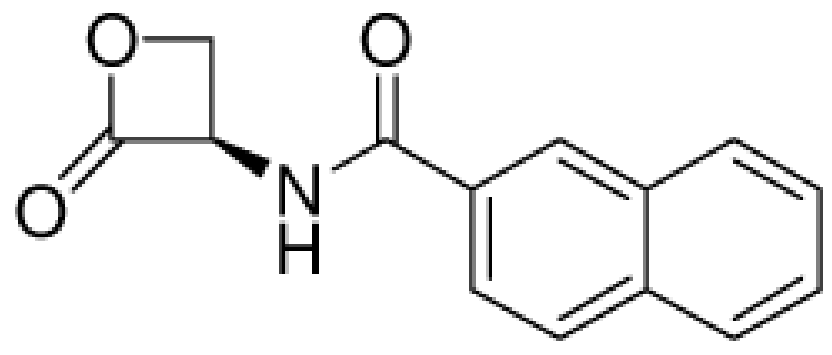

11j<smiles>O=C(NC1CCOC1=O)c1ccc2ccccc2c1</smiles>

$102 \pm 21$

$50,000 \pm 19,000$

$160 \pm 40$

$3,200 \pm 800$

$>100,000$ 


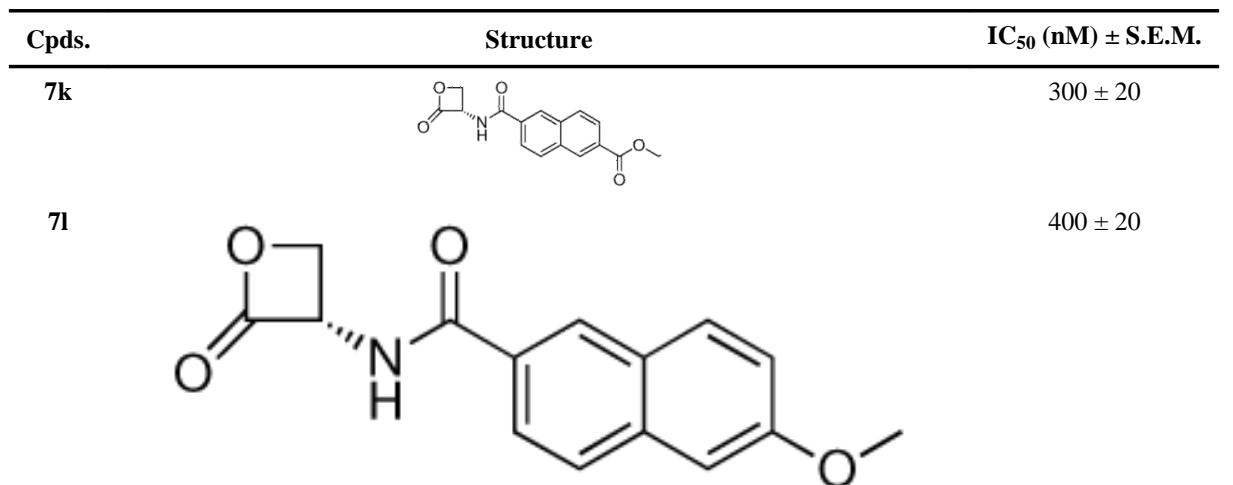

$7 m$

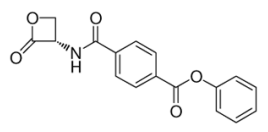

$300 \pm 100$

$7 n$

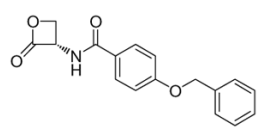

$90 \pm 10$

$7 \mathrm{~g}$

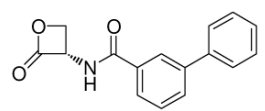

$4,400 \pm 1,200$

$7 \mathrm{~h}$

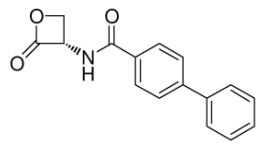

$115 \pm 13$ 


\section{Table 3}

Effects of Compound $7 \mathbf{h}$ on Michaelis-Menten Constant $\left(K_{\mathrm{m}}\right)$ and Maximal Rate of Reaction $\left(\mathrm{V}_{\max }\right)$ of Recombinant NAAA expressed in HEK-293 Cells.

\begin{tabular}{lccc}
\hline Compound 7h $(\mathbf{n M})$ & $\mathbf{0}$ & $\mathbf{1 0 0}$ & $\mathbf{2 0 0}$ \\
\hline$K_{\mathrm{m}}(\mu \mathrm{M})$ & $162.2 \pm 9.0$ & $128.7 \pm 32.8$ & $156.5 \pm 23.8$ \\
$\mathrm{~V}_{\max }(\mathrm{nmol} / \mathrm{min} / \mathrm{mg})$ & $17.9 \pm 1.6$ & $10.8 \pm 2.5^{*}$ & $6.2 \pm 0.2^{* *}$ \\
\hline
\end{tabular}

See Experimental Section for details.

** $\mathrm{P}<0.01$;

* $\mathrm{P}<0.05$ vs vehicle 